\title{
Template synthesis of nanomaterials
}

\author{
T.L. Wade ${ }^{\mathrm{a}}$ and J.-E. Wegrowe
}

LSI, École Polytechnique, CNRS-UMR 7642 \& CEA/DSM/DRECAM, 91128 Palaiseau Cedex, France

Received: 6 October 2004 / Accepted: 15 November 2004

Published online: 18 January 2005 - (C) EDP Sciences

\begin{abstract}
We present an overview of template synthesis as it applies to our nanomaterials research. This bottom-up approach is motivated by our desire to find an alternative to the big, top-down approaches to nanoscience, such as clean-rooms and X-ray lithography. Using universally available templates and materials, and very modest synthesis techniques, we have created a variety of interesting and useful structures. Starting with homogeneous ferromagnetic nanowires, we were able to study and manipulate spin-dependent transport. Next, we branched into multi-layer GMR and spin-valve structures for spintronics. As a side trip, we put carbon-encapsulated fullerene nanoparticles into nanopores for ballistic magnetoresistance studies. Carbon nanotube molecules were grown in templates by CVD self assembly. The carbon nanotubes grown using a cobalt catalyzer show spin-valve, ballistic transport, and Coulomb blockade effects. Very recently, we have started to study templated semiconductor nanorods with the amazing result that their behaviour is very similar to that of the carbon nanotubes and can be reduced to a scaling law. Essentially, the template acts as a skeleton for the nanoscale synthesis and macroscale contact of an infinite variety of materials and structures. It is our hope that by the following examples we demonstrate that high quality nanoscience research is available to everybody.
\end{abstract}

PACS. 73.23.Ad Ballistic transport - 73.23.Hk Coulomb blockade; single-electron tunneling - 75.75.+a Magnetic properties of nanostructures - 81.16.-c Methods of nanofabrication and processing - 81.16.Be Chemical synthesis methods - 81.16.Dn Self-assembly

\section{Inspiration}

Forty-five years ago Richard Feynman gave a talk titled 'There's Plenty of Room at the Bottom'. Here he described a new realm of science on the small scale, where new properties would be discovered and things could be made at the molecular and atomic level like nature does everyday. It is from this speech that the term 'bottom-up' was born. Today the philosophy of small is realized particularly in the electronics industry and is formalized in Moore's law. The processes used by science and electronics to make increasingly smaller 'nano' scale depends on big instruments and artificial environments like high vacuum chambers and clean rooms. The reliance on big machines to make small devices is very confining and limits nanoscience to megabucks. This dependence on 'hi-tech', 'low-pressure', 'clean-room' facilities is not necessary, cripples science, and leaves it in the hands of the financially blessed.

Much of the progress in nanotechnology has been achieved in the electronics industry. So successful is it that now research is following the initiatives of industry and research funding seems to be totally co-opted by this trend.

\footnotetext{
a e-mail: travis.wade@polytechnique.fr
}

It is very ironic that in order to make things small one has to be very big.

Many researchers are trying to bridge the micro-nano gap by reducing the size of existing materials and structures. As devices become smaller and faster, properties change due to size and limits are found. For example, the capacitance and carrier mobility of silicone limits its speed. Vacuum sputtered aluminium was found to be too resistive for device interconnects and the unthinkable process of aqueous copper electrodeposition was introduced into the temple of 'clean-room' fabrication. Lithography can be improved to approach atomic scale dimensions [1]. The cost and difficulty, however, will mount, once again leaving the small guy in the cold.

Another drawback of the mega/industrial approach to nanoscience is that it is cumbersome and difficult to manoeuvre. It is necessary to "retool" every time there is a change of technology. If a researcher decides to a use a new material he could be guillotined for polluting a molecular beam epitaxy (MBE) chamber by a new or magnetic element. A tremendous advantage of template synthesis, electrodeposition, and chemical vapor deposition (CVD) are the ease and speed with which they can be changed and applied to new research areas. Therefore, there are still many opportunities to explore other means of nanoscience and nanoscale fabrication. In these few pages we show that 


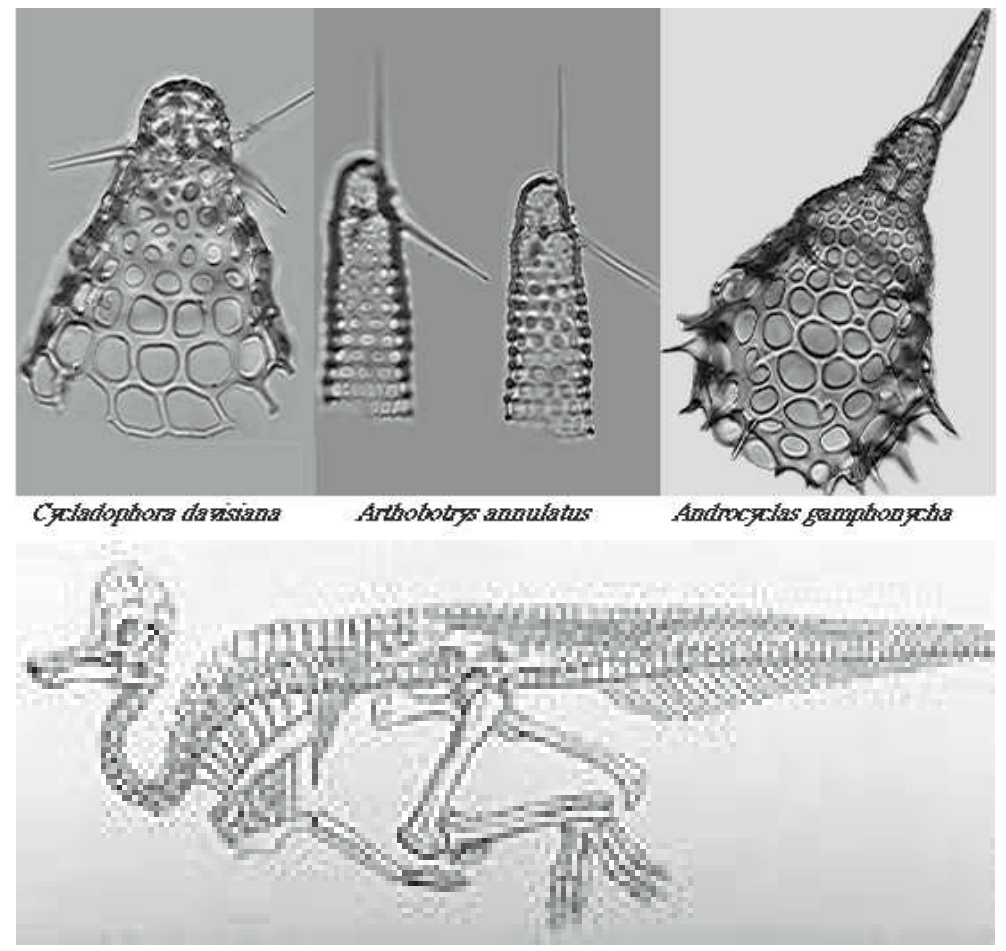

Fig. 1. Self-assembled biological templates.

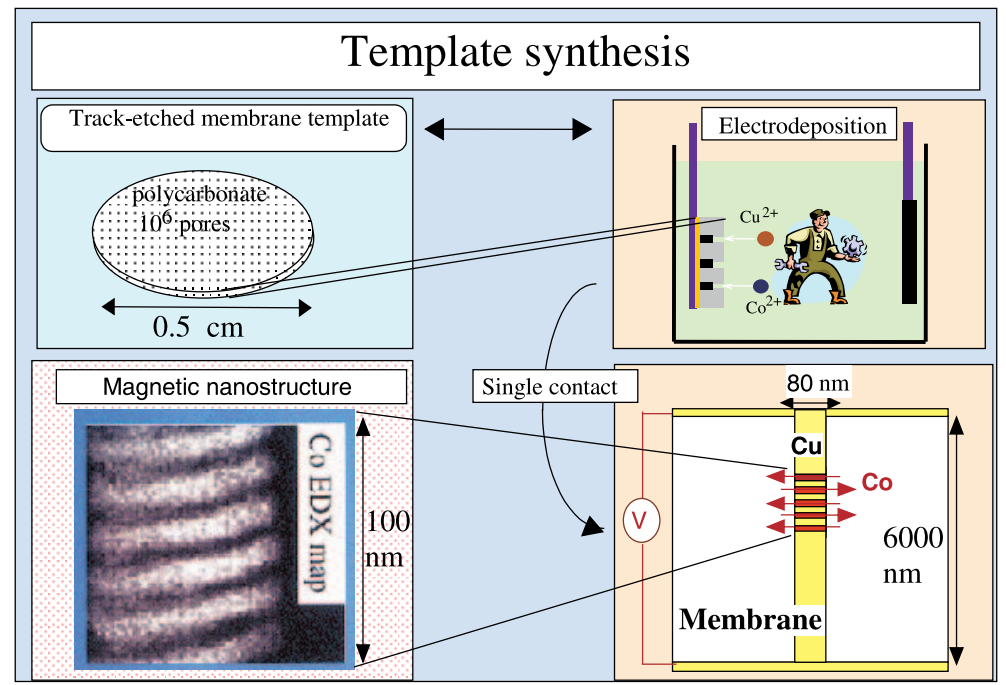

Fig. 2. Scheme of the template synthesis of nanowires. This scheme is of the synthesis of $\mathrm{Co} / \mathrm{Cu}$ multiplayer nanowires.

with template synthesis one can address nanotechnology in a small but significant and fundamental way.

The role of the template is two fold. First, it allows the reproduction of the structure with the best possible reproducibility and plays the role of a skeleton in order to organize the different functions of a device, the active components and the different interfaces (building blocks, electric contacts, gate voltage, bias fields, optical sensors...) on a rigid body, Figure 1. For example, the role of the template is to allow the manipulation of the building blocks without the need of a microscopic tip (no systematic use of atomic force microscopy, AFM, or scanning tunnelling microscopy, STM) or without the need of top-down processes (lithography, FIB, or lift-off). Second, it is used to link the structure to the macroscopic word, i.e. the contacts.

In the scheme of template synthesis it is possible to identify three different steps: (1) the creation of the building blocks, (2) the assembly of the building blocks into a functional architecture within the template, and (3) the fabrication and control of the contact to the macroscopic world. The first and second steps coincide for metallic nanowires or semiconductors and are made by electrodeposition, Figure 2. For carbon nanotubes and silicon 
nanowires a catalytic layer is made by electrodeposition followed by CVD for the carbon nanotubes or solidliquid-vapour growth for the silicon nanowires. The final step, and perhaps most important, is the contact of the nanoscale object to the macroscopic world.

\section{Templates}

Template synthesis of nanostructures has developed independently [2] in various fields of nanotechnology and many good reviews are available [2-22]. The most common templates are ion-track etched membranes [9] and anodized aluminium [23].

Ion-track etched membranes are made industrially for filters and the science of ion-track templates is well developed [24]. Possin was the first to electrodeposit metallic nanowires in the diamond shaped pores of ion-track etched mica for superconducting studies of Sn nanowires in 1970 [25]. He was able to produce a membrane template by etching the latent ion-tracks produced by uranium in muscovite mica [24]. Next, Possin used the membrane as a mould, template, to electrodeposited wires of In, Sn, and $\mathrm{Zn}$ as small as $30 \mathrm{~nm}$ and 10 microns long. Due to the low density of pores and resulting wires, he was able to contact single nanowires. Five years later, Kawai and Ueda electrodeposited cobalt and nickel into the pores of alumina and proposed possible applications for magnetic memory [26]. In 1984 Williams and Giordano improved the techniques of Possin to produce $8 \mathrm{~nm}$ diameter wires [27]. By the late 80's and early 90's Vetter and Sphor, Whitney et al., and Martin extended metallic electrodeposition to ion-track etched plastic membranes [2-4,28,29]. Charles Martin also coined the term 'template synthesis' $[2,30]$ as well as extensively developing the technique. Since these seminal experiments, the use of template synthesis for nanowires has exploded [8-10,12,14-16, 18,20,21,31-43].

The variety of materials includes but is not limited to: magnetic nanowires and superlattices for anisotropic magnetoresistance, AMR, giant magnetoresistance, GMR, and tunnelling magnetoresistance, TMR, memory applications $[7,11,32,44-67]$, polymer nanowires and nanotubes [68,69], semiconductor nanowires [70], rectifiers $[37,71,72]$, single-crystal nanowires [36,73-85], superconducting nanowires [86-90], and transistors [91]. Also, there is continued use of track-etched mica [92-94]. The aim of this article is to give a superficial overview of the our results with template synthesis and to call attention to our unique contributions in this important field.

Ion-track etched plastic templates, like mica, have been exposed to an ion source [24]. The ions form randomly spaced damage tracks through the membranes that can be chemically etched to remove the damage path leaving nanodimensional holes that transverse the membrane, Figure 3. These membranes are commercially available as filters and are usually polycarbonate with pore diameters ranging from $10 \mathrm{~nm}$ to $2000 \mathrm{~nm}$ [95].

The anodization of aluminium to form a nanoporous membrane is of intense technological interest as a selfassembled template $[23,39,96-108]$. Alumina membranes

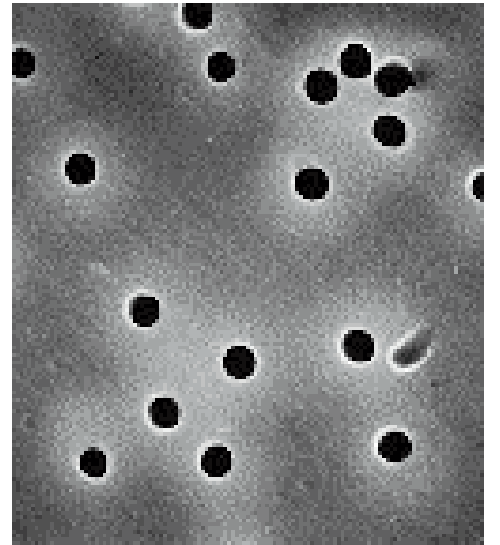

Fig. 3. SEM micrograph of a commercial ion-track etched polycarbonate membrane.

and electrodeposition inside the pores are now being developed due to the possibility of making arrays of carbon nanotubes of controlled length and pore diameter [13,109-122]. Anodization is an electrochemical process by which nanosized pores self-form in an insulating oxide film of alumina. The diameter and length can be varied from 5 to $300 \mathrm{~nm}$, Table 1, and the length depends on the anodization time. For different electrolytes the typical pore diameters increase from $5-33 \mathrm{~nm}$ for $\mathrm{H}_{2} \mathrm{SO}_{4}$ to $30-70 \mathrm{~nm}$ for oxalic acid and $150-267 \mathrm{~nm}$ for $\mathrm{H}_{3} \mathrm{PO}_{4}$, depending on the voltage. These pore diameters are often overstated because many studies follow anodization by pore widening in $\mathrm{H}_{3} \mathrm{PO}_{4}$ to improve the uniformity of the membrane and remove any residual oxide at the pore bottom. Highly ordered porous alumina has a porosity of $10 \%$ [123] with very high pore densities of $10^{11}$ pores $/ \mathrm{cm}^{2}$. The pore diameter growth rate increases with increasing voltage by $1.29 \mathrm{~nm} / \mathrm{V}$ and the pore spacing by $2.5 \mathrm{~nm} / \mathrm{V}[96]$. These values are obscured by changes in solution temperature and electrolyte concentration. The popularity of alumina is due to its exceptional thermal properties (necessary for CVD applications), ease of fabrication, and its versatility as far as pore diameter and pore length. Porous aluminium is widely used for the formation of metallic and semiconductor nanowires [13,82,123-144]. and even carbon nanotube transistors [145].

Recently, a new type of self-assembled template has been developed [152]. It is made by the annealing of spincoated diblock copolymer between two electrodes under a DC field. This results in a template of controlled thickness with pore densities comparable to alumina, $\sim 1 \times 10^{11} / \mathrm{cm}^{2}$.

\section{Samples}

\subsection{Ion track-etched membranes}

Most of our efforts are concerned with ion-track etched membranes for nickel nanowires, $\mathrm{Co} / \mathrm{Cu}$ multilayers, and $\mathrm{Co} / \mathrm{Cu} / \mathrm{Co}$ pseudo spin-valves [153-168]. A polycarbonate membrane like that in Figures 2, 3, and 4a can be used for nanowire formation in the following manner: first, through 


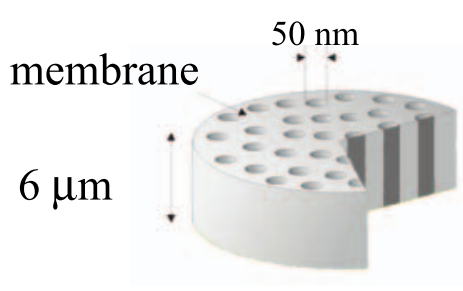

(a)

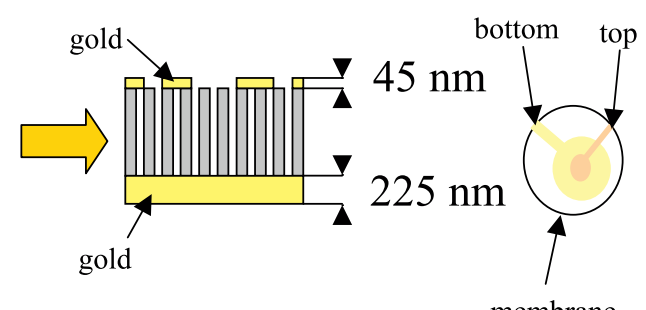

(b)

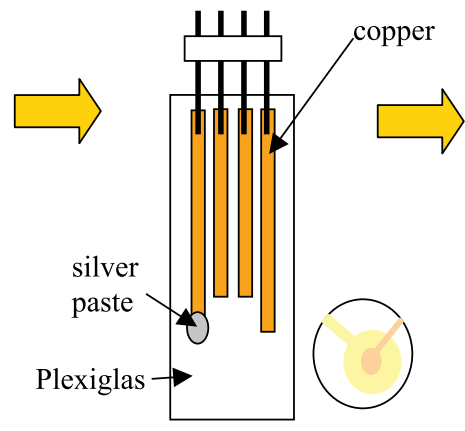

(c)

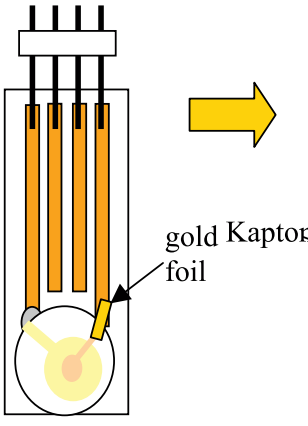

(d)

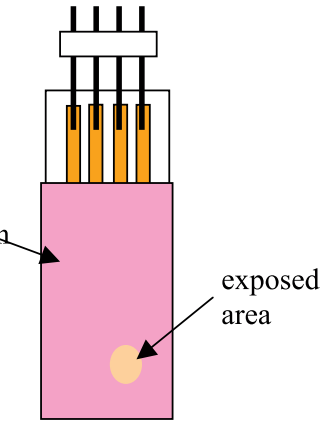

(e)

Fig. 4. Steps of sample fabrication using ion track-etched polycarbonate membrane: (a) membrane, (b) sputtered gold contacts, (c) sample holder, (d) membrane on holder with contacts, and (e) Kapton isolation of sample holder and membrane for electrodeposition.

Table 1. Pore diameters and anodization conditions from selected references.

\begin{tabular}{|c|c|c|c|c|}
\hline Reference & $\begin{array}{l}\text { Pore Diameter } \\
(\mathrm{nm})\end{array}$ & Voltage & Temperature $\left({ }^{\circ} \mathrm{C}\right)$ & Electrolyte \\
\hline \multirow[t]{3}{*}[146]{} & $5-8$ & 15 & 10 & $10 \% \mathrm{H}_{2} \mathrm{SO}_{4}$ \\
\hline & 30 & 40 & 20 & $3 \%$ Oxalic acid \\
\hline & 150 & 130 & 7 & $10 \% \mathrm{H}_{3} \mathrm{PO}_{4}$ \\
\hline [121] & 22 & 27 & 2 & $3 \mathrm{M} \mathrm{H}_{2} \mathrm{SO}_{4}$ \\
\hline$[147]$ & 28.6 & & & \\
\hline$[148]$ & 45 & 40 & 0 & $0.2 \mathrm{M}$ Oxalic acid \\
\hline \multirow[t]{2}{*}[149]{} & 70 & $30-60$ & 1 & 0.3 M Oxalic acid, \\
\hline & 35 & $18-25$ & 1 & $20 \% \mathrm{H}_{2} \mathrm{SO}_{4}$ \\
\hline \multirow[t]{2}{*}[150]{} & $40-50$ & & & Oxalic acid \\
\hline & $10-15$ & & & $\mathrm{H}_{2} \mathrm{SO}_{4}$ \\
\hline$[116]$ & 33 & 40 & 15 & $0.2 \mathrm{M}$ Oxalic acid \\
\hline \multirow[t]{2}{*}[111]{} & 10 & 15 & & $15 \% \mathrm{H}_{2} \mathrm{SO}_{4}$ \\
\hline & 50 & 45 & & $0.3 \mathrm{M}$ Oxalic acid \\
\hline [122] & 35 & 40 & 12 & $0.3 \mathrm{M}$ Oxalic acid \\
\hline \multirow[t]{3}{*}[151]{} & 33 & 25 & 10 & $1.7 \% \mathrm{H}_{2} \mathrm{SO}_{4}(0.3 \mathrm{M})$ \\
\hline & 67 & 40 & 1 & $0.3 \mathrm{M}$ Oxalic acid (2.7\%) \\
\hline & 267 & 160 & 3 & $10 \% \mathrm{H}_{3} \mathrm{PO}_{4}$ \\
\hline
\end{tabular}

a mask, $225 \mathrm{~nm}$ of $\mathrm{Au}$ is deposited on one side of the membrane, to serve as a cathode, and $45 \mathrm{~nm}$ of $\mathrm{Au}$ is deposited on the other side to serve as a contact electrode, Figure 4b.

The working electrode, cathode, is then connected with $\mathrm{Ag}$ paste, to $\mathrm{Cu}$ leads on a Plexiglas sample holder made in house, Figure 4c. The contact electrode is then connected, with $\mathrm{Au}$ foil strips and $\mathrm{Ag}$ paste to other $\mathrm{Cu}$ leads on the same substrate, Figure 4d. This assembly is wrapped in Kapton tape with the contact electrode exposed by an opening previously cut in the tape, Figure 4e. Kapton tape is inert in electrolyte solutions. The edges of the exposed contact electrode are sealed with paraffin. The exposed area of the membrane is a $0.2 \mathrm{~cm}^{2}$ circle.

The substrate-working electrode is connected to the working electrode lead of a potentiostat and the contact electrode is connected to the working electrode through a floating electrometer. The sample is then placed in a metal electrolyte, Figure 2, far enough to submerge the exposed area. Potentiostatic electrodeposition [169] of the 


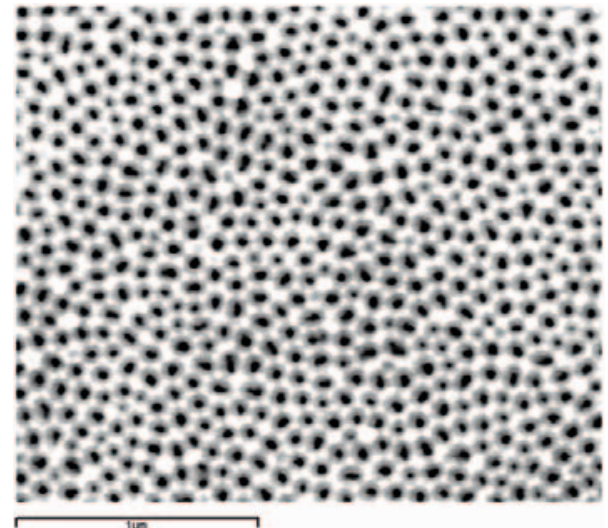

Fig. 5. SEM micrograph of the surface of an alumina membrane made by to-step anodization.

metal (M) is then performed in the pores of the membrane by means of the working electrode, equation (1),

$$
\mathrm{M}^{n+}+n \mathrm{e}^{-} \rightarrow \mathrm{M}^{0}
$$

where $\mathrm{M}(\mathrm{Co}, \mathrm{Cu}$, or $\mathrm{Ni})$ is the metal and $n$ is the number of electrons. This is possible since the contact electrode $\mathrm{Au}$ layer is porous enough to allow electrolyte to pass into the membrane, Figure 4b. For our measurements the left two electrodes on the sample placket are shorted together and the right two are shorted together. The sample holder was originally designed for four point measurements and could serve for such in the future.

\subsection{Alumina}

The same protocol can be used for alumina membranes. The membrane itself, however, is made by anodization. For anodization we usually use two-step anodization [99] on $0.5 \mathrm{~mm}$ thick $7 \mathrm{~mm}$ diameter aluminium circles, previously vacuum annealed at $600{ }^{\circ} \mathrm{C}$ for 10 hours. Typical anodization parameters are first to electropolish the $\mathrm{Al}$ in a solution of $25 \% \mathrm{HClO}_{4}$ and $75 \%$ ethanol at $10 \mathrm{~V}$ for 2-3 minutes. This results in a mirror like $\mathrm{Al}$ surface. The following step is to perform the anodization at a constant voltage for 5 minutes in a $0.3 \mathrm{M}$ oxalic acid solution. Next, we put the sample in a chromate dissolution solution, 60 grams/litre $\mathrm{H}_{3} \mathrm{PO}_{4} 15.5$ grams/litre $\mathrm{CrO}_{3}$, for 2 hours and 30 minutes at $37^{\circ} \mathrm{C}$. This dissolution process removes the oxide layer. It leaves, however, the hexagonal honey-comb pattern, which is the starting surface for the next, more ordered anodization. Finally, we repeat the anodization for the desired time. An example of a $40 \mathrm{~V}$ anodization is shown in Figure 5. At this voltage the growth of the $\mathrm{Al}_{2} \mathrm{O}_{3}$ layer is $150-200 \mathrm{~nm} /$ minute with pore diameters of $40-50 \mathrm{~nm}$. From this point, the alumina placket is mounted on the sample holder, as depicted in Figures $4 \mathrm{c}-\mathrm{e}$ for the polycarbonate membranes.

During the electroreduction, Figures 2 and 6 , of metallic ions, equation (1), from a metal cation solution, the potential between the working and the reference electrode, Figure 6 , is kept at a constant value $(-1.000 \mathrm{~V}$ vs.

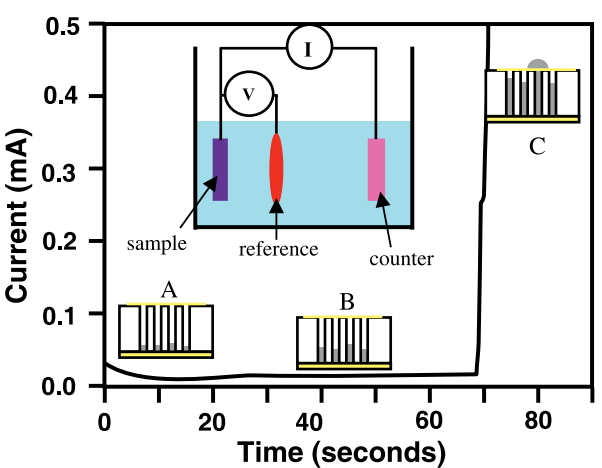

Fig. 6. Plot of current change versus time for electrodeposition of cobalt in a polycarbonate membrane. The inset is a drawing of a 3-electrode electrodeposition cell and drawings A, B, and $\mathrm{C}$ are different stages of nanowire growth corresponding to the timescale of the plot.

$\mathrm{Ag} / \mathrm{AgCl}$ for nickel electrodeposition) for potentiostatic control [169]. The counter electrode, Figure 6, serves as the current source for the system. The potential in the pores decreases as the wires grow from the cathode towards the contact electrode, and this potential is monitored by the floating electrometer. When the electrometer potential, i.e. the potential between the working and the contact electrodes, decreases to a threshold potential, a relay switch disconnects the working and the counter electrode, thus stopping the deposition. By adjusting the threshold potential it is possible to contact a single wire $[153$, 170]. The single-contact is aided by the large increase in current, Figure 6, and corresponding decrease in solution resistance, when the first wire makes contact with the contact electrode, which covers the entire surface of the membrane. Using these techniques we are able to single-contact a variety of nanostructures, Figure 7 . Whether a singlecontact has been achieved or not can readily be verified by the resistance, which can be calculated for a single wire,

$$
R=\rho_{M} l / a
$$

where $R$ is the resistance, $a$ the cross-sectional area of the wire, $\rho_{M}$ the resistivity of the metal, and $l$ the length of the wire. A $50 \mathrm{~nm}$ diameter nickel wire $6000 \mathrm{~nm}$ long has a resistance of about $260 \mathrm{ohms}$, depending on the resistance of the contacts.

\section{Results}

\subsection{Nickel nanowires}

The magnetoresistance plot for a single-contacted nickel nanowire of $50 \mathrm{~nm}$ is seen in Figures $8 \mathrm{a}$ and b model. The first thing to note about Figure 8 is that the resistance is much lower than predicted in equation (2), however, the sample was measured at $4 \mathrm{~K}$ where the resistance is about 2.5 times lower than ambient. The typical anisotropic magnetoresistance (AMR) shape is evident.

Proof of the AMR can be seen in the magnetoresistance curve themselves, Figures $8 \mathrm{a}$ and b. The anisotropic 


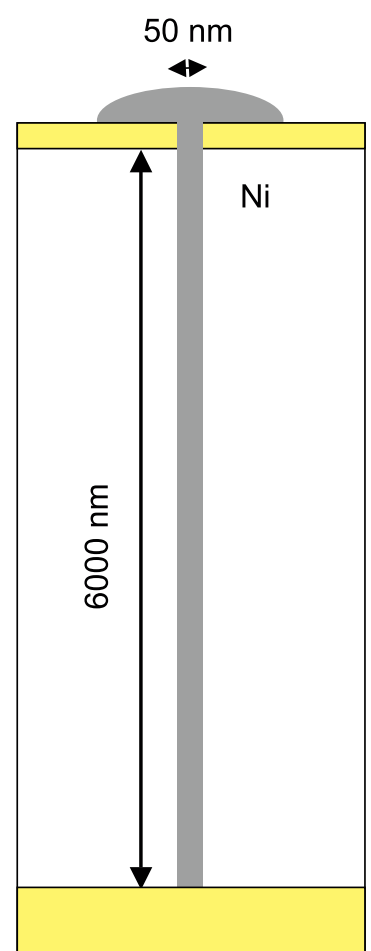

(a)

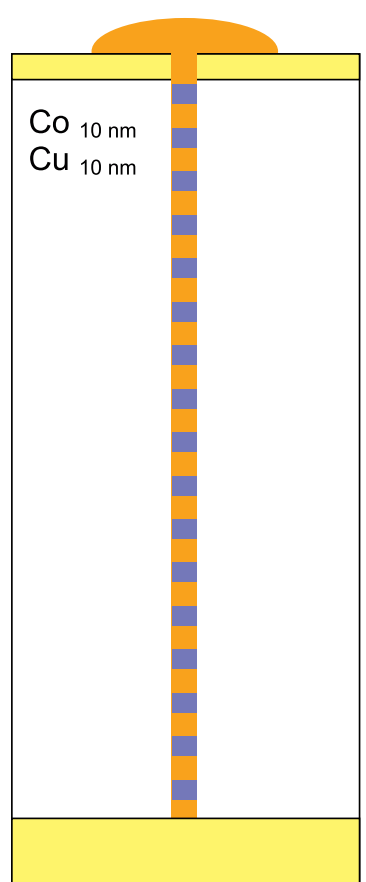

(b)

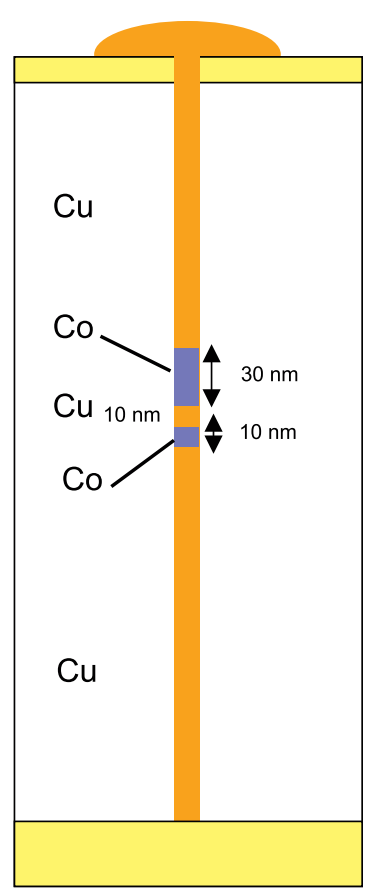

(c)

Fig. 7. Three examples of nanowires fabricated in membrane templates.

magnetoresistance is a well known effect (discovered by Thomson in 1857) which is due to the fact that the electrons are strongly scattered by the magnetic scattering centres if the current is parallel to the magnetization, but weakly scattered in the direction perpendicular to the magnetization [171]. The AMR is simply proportional to the square of the cosine of the angle $\varphi$ between the magnetization and the current. In our wires, the current direction coincides with the anisotropy axis. Furthermore, if the magnetization is uniform the effect of the external field is to rotate the magnetization around the anisotropy axis. As a consequence, the magnetic hysteresis loop $M(H)$ is simply related to the magnetoresistance hysteresis loop $R(H)$ by the relation,

$$
R(H)=R_{\min }+\Delta R \cos ^{2} \varphi \sim(M(H) / M s)^{2}
$$

where $\Delta R$ is the amplitude of the AMR, and $M s$ is the magnetization at saturation. Due to the fact that the anisotropy is parallel to the current direction, $R(H)$ is maximum and constant for a field parallel to the wire, and minimum $\left(R(H)=R_{\min }\right)$ for a saturation field perpendicular to the wire. The maximum amplitude of the hysteresis is measured with an external field perpendicular to the wire axis.

In a $\mathrm{Ni}$ nanowire, the magnetic moment rotates with varying the amplitude of the external field up to the switching field, $H_{s w}$, where a jump of the magnetization *occurs [153,154]. The magnetic hysteresis loop is composed of a reversible rotation of the magnetization (this is the envelop of the curve in Figure 8 defined by the succession of the minima of the potential energy $d E / d \varphi=0$ as a function of the field) and an irreversible jump from one metastable state to the next stable state defined by non equilibrium conditions. The irreversible jump occurs at a critical angle, $\varphi_{c}$, of the magnetization, and the corresponding switching field $H_{s w}$ (defined e.g. by the condition $d^{2} E / d \varphi^{2}=0$ in the Stoner-Wohlfarth model with the hypothesis of uniform jump). In the case of $\mathrm{Ni}$ nanowires, the jump occurs at the maximum switching field around $H_{s w}= \pm 3000$ Oe as expected for an infinite amorphous $\mathrm{Ni}$ cylinder, with the shape anisotropy field given by $H_{a}=4 \pi M_{s}$ where $M_{s}$ is the magnetization at saturation. This shows that there is no magnetocrystalline anisotropy involved: the $\mathrm{Ni}$ is composed of randomly oriented crystallites, with a size smaller than the magnetic exchange size (a few nanometers) [49]. From a magnetic point of view, the $\mathrm{Ni}$ is amorphous, and the shape anisotropy is perfectly uniaxial. The energy can be written with the sum of the anisotropy term and the Zeeman term $E=\left(M_{s} H_{a} / 2\right) \sin ^{2}(\varphi)-M_{s} H \cos (\theta-\varphi)$ where $\theta$ is the angle of the external field with respect to the wire axis.

The effect of current injection was studied with various experimental protocols. A simple approach of this phenomenon is presented below. Figure 9 is an expansion of a hysteresis area such as those of Figure 8 . The arrows indicate the point at which a large current density was injected. If the current is injected at fields $H_{s w}^{i}$ corresponding to the magnetic state defined by the angle, $\varphi=\varphi_{c}-\Delta \varphi$, then a jump occurs from the uniform state to the other uniform state. This final state corresponds to that measured in the hysteresis loop with 

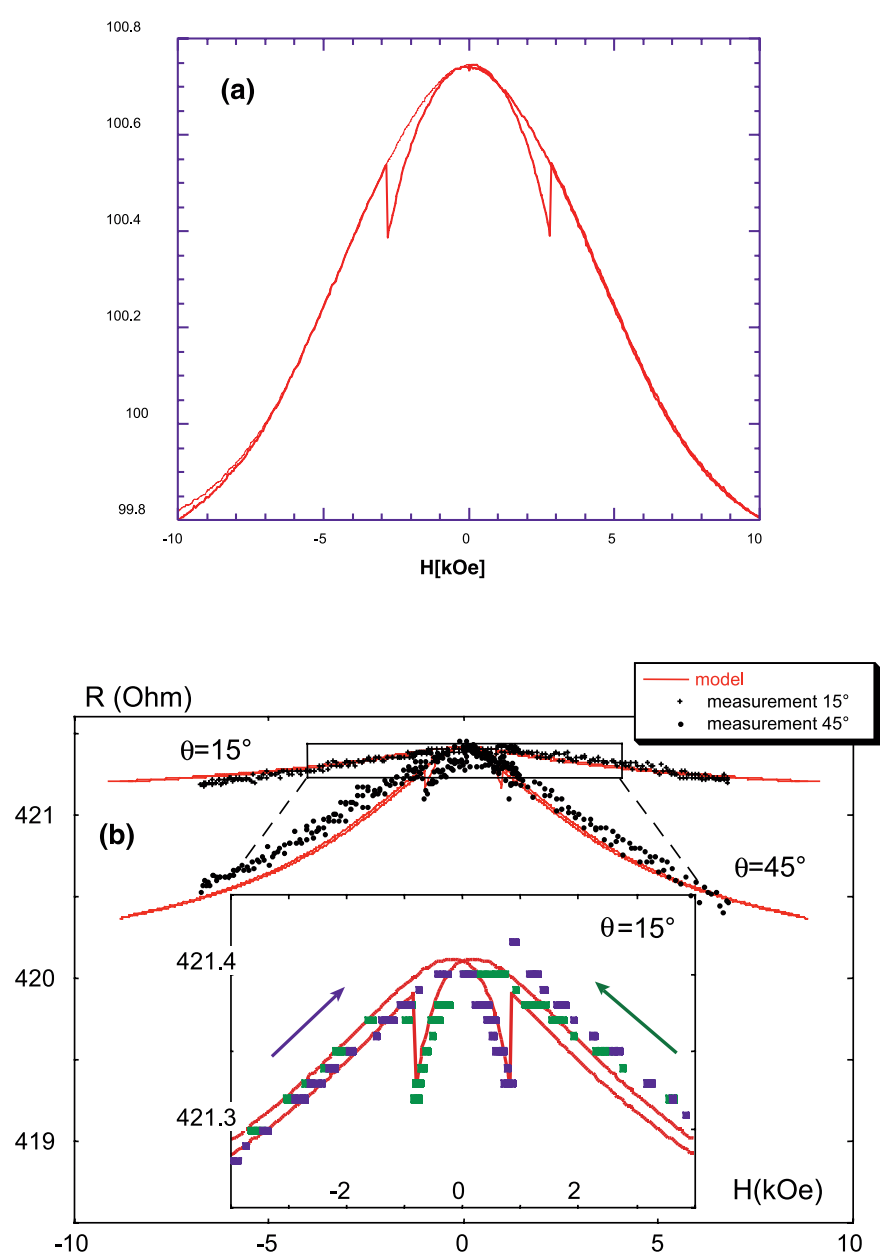

Fig. 8. Magnetoresistance curve of a single-contacted nickel nanowire at room temperature, (a) applied field close to $\theta=$ $90^{\circ}$, (b) $\theta=10^{\circ}$ and $\theta=45^{\circ}$, the red line is the theoretical curve for uniform rotation.

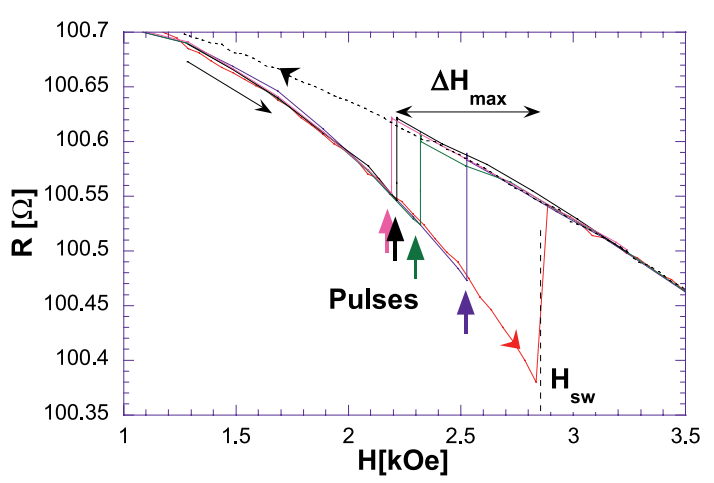

Fig. 9. Expansion of the irreversible hysteresis part of Figure $8 \mathrm{a}$ indicating the effect of high-density current injection.

decreasing applied field (reversible part). The jump would also occur if the current is injected at any field between $H_{s w}^{i}$ and $H_{s w}$. The maximum distance, $\Delta H=H_{s w}^{i}-H_{s w}$, constitutes a measure of the angular variation, $\Delta \varphi$, produced by the current pulse. Knowledge of the magnetization configurations in the single-contacted Ni nanowires is necessary for studies of the effect of a high current density

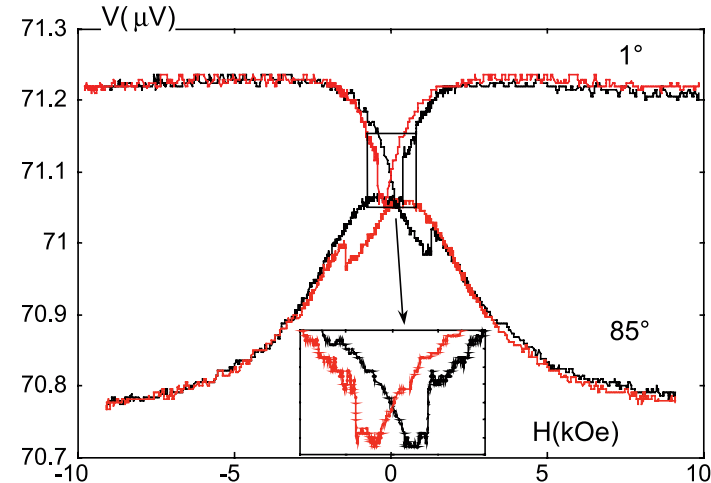

Fig. 10. AMR of a single-contacted cobalt nanowire at different angles to external field.

injected close to an unstable state of the magnetization. These studies find a direct application in magnetic random access memory (M-RAM), where the scaling of the memory units down to nanometric scales render the writing of the memory very difficult with an induced magnetic field (induction is a macroscopic effect which does not scale well). Theoreticians have predicted the possibility of directly switching the magnetization, due to the effect of the spin carried by the conduction electrons [172-175]. It can be observed (Fig. 9) that the effect of injecting about $10^{7} \mathrm{~A} / \mathrm{cm}^{2}$ current density (this corresponds to about $1 \mathrm{~mA}$ in the sample) is to provoke the magnetization reversal [155]. This discovery was the first observation of current induced magnetization switching (CIMS) and opened the way to a series of measurements on various structures, and intense research activity related to the application to MRAM (see next paragraph). The direct effect of Joule heating, induced Oersted field, or field gradient has been ruled out [167]. The physical mechanism responsible for the effect is still controversial. However, it has been shown that the effect of $1 \mathrm{~mA}$ current injection leads to a variation of about $50 \%$ of the switching field, or $25 \%$ of the anisotropy field $[158,163,164]$. These values have been corroborated by time resolved experiments (with sub-microsecond time resolution), where the potential energy barrier variation due to current injection was measured to be around $50000 \mathrm{~K}(4 \mathrm{eV})$ for an anisotropy energy of $2 \times 10^{5} \mathrm{~K}[160,168]$. This effect is of fundamental interest and controlling it would lead to an efficient writing process for magnetic random access memories (MRAMs) at a nanoscopic scale [160].

The same studies performed with Co nanowires (Fig. 10) are more difficult because the hysteresis loop shows the creation and annihilation of magnetic domain walls, and the micromagnetic structure is difficult to characterize [154]. This is the reason why the rest of this study is performed with $\mathrm{Ni}$ nanowires instead of $\mathrm{Co}$ nanowire. However, the property of making big crystallites (few $100 \mathrm{~nm}$ to micrometric) with electrodeposited $\mathrm{Co}$ in nanowires will be exploited for layered $\mathrm{Co}$ and $\mathrm{Cu}$ inside the pores (see next Sect.).

The method just described allows the micromagnetic configurations of the nanowires to be studied at a 


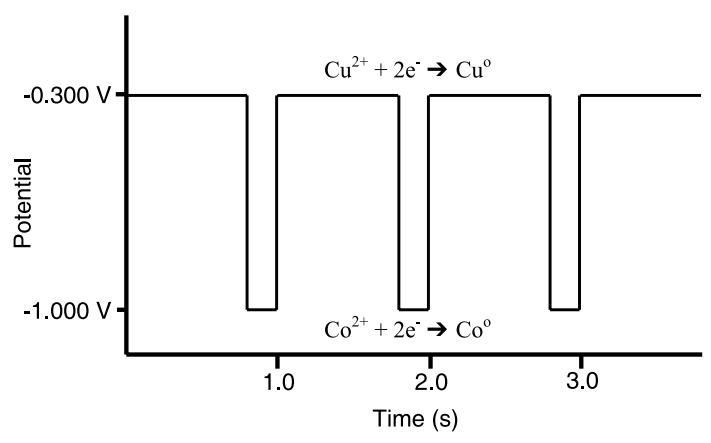

Fig. 11. Voltage versus time profile for electrodeposition of $\mathrm{Co} / \mathrm{Cu}$ multi-layered nanowire.

nanoscopic scale. Note, however, that the wire is composed by about $10^{7}$ spins (less than $10^{5}$ for the Co layers, see below), which corresponds to a magnetic moment of about $10^{-15} \mathrm{emu}$. In comparison, the best commercial magnetometers (SQUID magnetometry) give a precision of about $10^{-7}$ emu. Such structures cannot be measured with usual magnetometry, but some recent development with micro-SQUID or micro-hall sensors technology are able to reach such precision $[45,48]$. However, the singlecontacting method allows one to access, through the magnetoresistance properties, the micromagnetic configurations at these very small scales.

\subsection{Co/Cu multi-layer nanowires}

The methods used to make and contact the nickel nanowire can be modified to make more complicated structures such as Figure 7b. This is an idealized electrodeposited cobalt/copper nanowire superlattice that causes physical phenomenon such as giant magnetoresistance (GMR) [11,44,56,176]. Structures like this are useful in devices such as read/write heads in computer hard drives [177] and are also useful for thermoelectric power $[161,178]$. The electrodeposition solution used in this case contains two cations, $\mathrm{Co}^{2+}$ and $\mathrm{Cu}^{2+}$, Figure 2 electrodeposition. The electrochemistry of these metal ions facilitates the deposition of these elements from the same solution because their redox potentials are well separated, $-0.476 \mathrm{~V}$ for $\mathrm{Co}^{2+}+2 \mathrm{e}^{-} \rightarrow \mathrm{Co}^{\circ}$ and $-0.040 \mathrm{~V}$ for $\mathrm{Cu}^{2+}+2 \mathrm{e}^{-} \rightarrow \mathrm{Cu}^{\mathrm{o}}$ vs. SCE [179]. This means that with a solution of $\mathrm{Co}^{2+}$ and $\mathrm{Cu}^{2+}$ one could deposit pure copper without any cobalt by poising the potential more positive than $-0.476 \mathrm{~V}$ versus a SCE reference electrode. When, however, the potential is more negative of this value: cobalt will deposit along with copper. With this in mind, one can prepare a solution with a very high concentration of $\mathrm{Co}^{2+}$, perhaps $100 \mathrm{~g} / \mathrm{l}$, and a very low concentration of $\mathrm{Cu}^{2+}$, perhaps $1 \mathrm{~g} / \mathrm{l}$. Now, by cycling the deposition potential with a profile like Figure 11, it would be possible to form a superlattice with pure copper layers cobalt layers with a small percentage of copper [44]. The next thing to determine is the relative deposition times for the cycle. Due to the spin diffusion length of spin polarized electrons in copper, the necessary anti-ferromagnetic

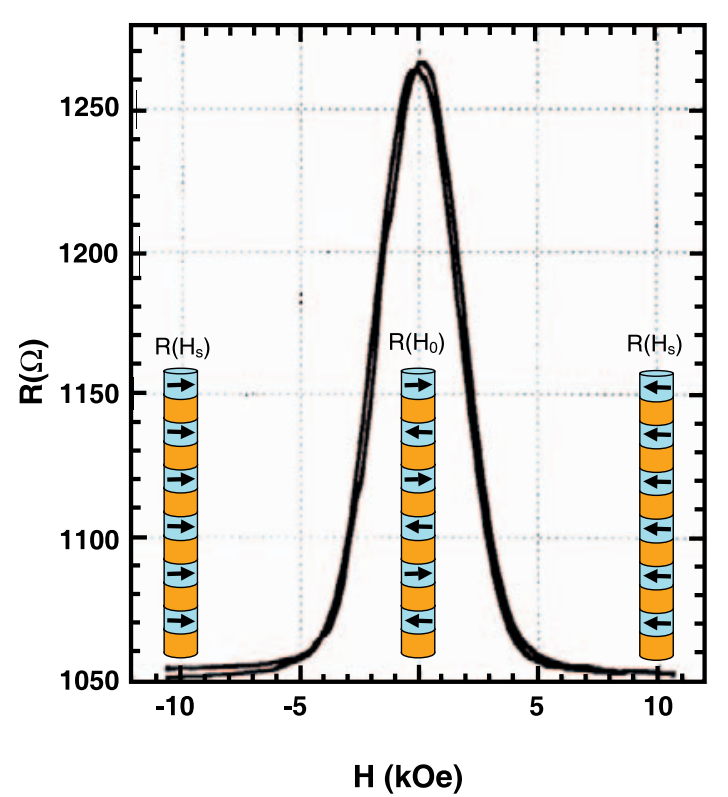

Fig. 12. GMR of a single-contacted $\mathrm{Co} / \mathrm{Cu}$ multilayer nanowires.

coupling of the cobalt layers, and other morphological aspects; a structure consisting of layers of $10 \mathrm{~nm}$ thick cobalt separated by $10 \mathrm{~nm}$ thick copper layers is optimal for electrodeposited mutilayers [44]. The necessary information is now in hand for forming single GMR nanowires from the dual ion solution. Example: it takes 69 seconds to deposit a $6000 \mathrm{~nm}$ long wire of cobalt at a potential of $-1.000 \mathrm{~V}$, Figure 6 . This corresponds to a deposition rate of $86.9 \mathrm{~nm} /$ seconds for cobalt or 0.11 seconds to form a $10 \mathrm{~nm}$ thick layer of cobalt. For copper it takes 0.90 seconds to form a $10 \mathrm{~nm}$ thick layer at $-0.300 \mathrm{~V}$. A bilayer of Co $10 \mathrm{~nm} / \mathrm{Cu} 10 \mathrm{~nm}$ is $20 \mathrm{~nm}$ so 300 bilayers of Co $10 \mathrm{~nm} / \mathrm{Cu} 10 \mathrm{~nm}$ can be formed in a $6000 \mathrm{~nm}$ thick membrane in 303 seconds, Figure 11. A possible pitfall of this scheme is that during copper deposition dissolution of the cobalt layer can occur [180], reverse of equation (1). However, this reaction is slow and only results in a slightly thinner cobalt layer. Other researchers have used a similar approach to $\mathrm{Co} / \mathrm{Cu}$ multiplayer nanowires using constant current or charge electrodeposition $[11,12]$. The constant potential technique is easier because potentiostatic deposition is independent of the sample area whereas coulometric deposition is directly dependent on the sample area.

Figure 12 is the GMR curve of a $\mathrm{Co} / \mathrm{Cu}$ multi-layer electrodeposited in a polycarbonate membrane. An elemental EDX map of an actual multilayer nanowires is shown in Figure 2, magnetic nanostructure. The curve shows a resistance change of $20 \%,\left(R\left(H_{0}\right)-\right.$ $\left.R\left(H_{s}\right)\right) / R\left(H_{s}\right)$. The diagrams represent the idealized orientation of the magnetic moments of the cobalt layers (blue) at different areas of the curve. At zero magnetic field $\left(\mathrm{RH}_{0}\right)$ the cobalt magnetic moments (arrows) are aligned antiparallel to each other due to dipole interaction. The exchange coupling is negligible through the $10 \mathrm{~nm}$ thick copper layers (orange). In this configuration, electrons travelling through the wire, current 


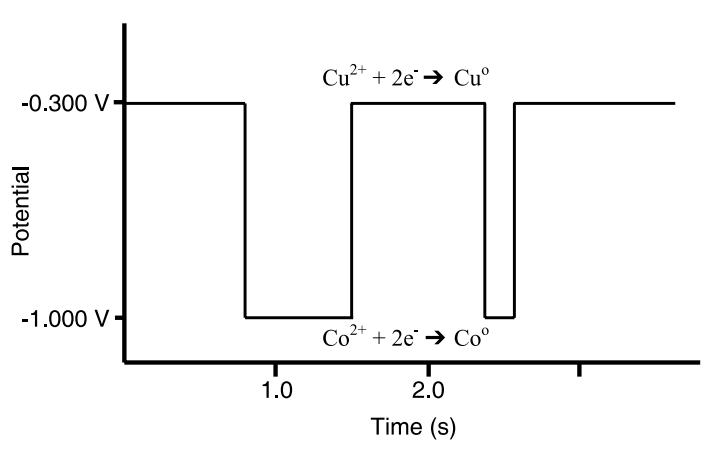

Fig. 13. Voltage versus time profile for electrodeposition of a spin-valve GMR nanowire.

perpendicular to the geometric plane of the magnetic layers (CPP geometry), experience fluctuating magnetic moments, which scatter the electrons and increase the resistance of the wire. At saturation fields $\left(R\left(H_{s}\right)\right)$ the moments are aligned in each layer so the electrons follow a less tortuous path and thus the wire has a lower resistance. An important criteria for large GMR signals is a well defined (atomic scale) interface between the cobalt and copper layers. This system is aided by the fact that cobalt and copper are metallurgically immiscible [180-183]. As mentioned earlier, there is a small percentage of copper in the cobalt layers, however, this is not detrimental to the GMR effect $[11,52]$. The advantage of GMR, other than its large signal, is that is not required for the wire to be perpendicular to the external field to be seen. However, no individual hysteresis can be seen due to the average signal of many layers as depicted in Figures $7 \mathrm{~b}$ and 12.

\subsection{Spin valves}

From our experience with the nickel nanowires and the $\mathrm{Co} / \mathrm{Cu}$ multilayers, we were able to make even smaller structures, such as Figure 7c. Structures like this are made by a modification of the GMR electrodeposition cycle of Figure 11 by increasing the cobalt deposition time by three and making the cycle one time, Figure 13. This is the pseudo spin-valve structure and an enlargement is shown in Figure 14. Pseudo means that the coupling between the two ferromagnetic layers is not due to ferromagnetic or antiferromagnetic exchange interaction (so called magnetic exchange biasing) but is caused by dipolar interactions. This is due to the fact that the buffer layer is thick with respect to RKKY exchange interactions (2 to $3 \mathrm{~nm}$ ). The system is a pillar structure and can be thought of as a spin polarizer of the current (the "fixed" layer) and a probe, or "free" layer in analogy with spin-valve terminology. The probe is $10 \mathrm{~nm}$ thick and 50 to $25 \mathrm{~nm}$ in diameter [166]. If the polarizer is fixed (e.g. if one of the layer has a stronger anisotropy), and if the layer has a uniaxial anisotropy the system can be reduced to a two-state system. The first condition is easy to obtain by depositing a thicker layer (typically $30 \mathrm{~nm}$ ). The second condition can be performed by using an amorphous metal with a very thin layer (planar anisotropy). However, as already

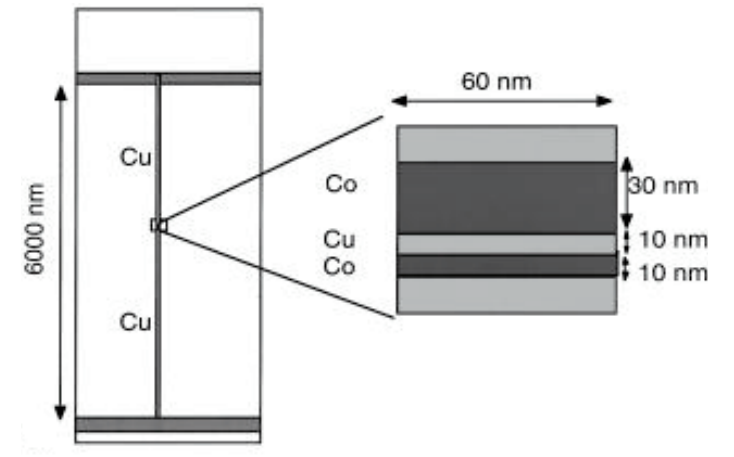

Fig. 14. Idealized spin-valve structure.

mentioned, the electrodeposited Co is structured in the form of big crystallites, larger than the layer thickness. The Co layer is hence a single crystal, usually with a hcp structure, and with the c-axis statistically preferentially oriented perpendicular to the wire axes [12].

With the spin-valve structure, one has the advantages of the AMR features of the homogeneous nickel wires with the advantages of the large signal of the multilayer structures. In this system, the current is spin-polarized perpendicularly to the displacement of the electrons in the first ferromagnetic layer in this current perpendicular to plane (CPP) geometry and enables spin injection with well-defined spin polarization in the next ferromagnetic layer. The spin diffusion length of electrodeposited cobalt and copper is of the order of some tens of nanometers. This spin polarization allows the magnetization states to be observed with GMR measurements. Beyond the GMR effect, the spin injection may lead to current induced magnetic switching (CIMS) [168].

The GMR accounts for the relative orientation of the two cobalt layers in Figure 15a. The current injection is performed at fixed external field, Figure 15b-expansion of minor loop from 15a. The magnetic orientation of the thicker, fixed, cobalt layer of the spin valve is determined by the external field and the magnetization of the thinner, free, cobalt layer can be changed by current injection. Now we have a nanodevice with two states that can be changed by current injection. This has tremendous applications in the field of MRAMs.

\section{Carbon nanotubes and silicon and tellurium}

\subsection{Carbon nanotubes}

Another exciting field is that of molecular electronics with the prospect of using molecules like carbon nanotubes or DNA for electronics $[184,185]$. Template synthesis offers a frame for molecular device construction. Alumina membranes are a very widely used template for the growth of carbon nanotubes [109-120,147,186-189]. Multi-wall carbon nanotubes (MWNT) were grown by a CVD reaction in the porous of alumina for transport measurements, Figure 16 [190]. The alumina membranes were made, as previously described, by anodization of aluminium in $0.3 \mathrm{~mol} / \mathrm{l}$ 


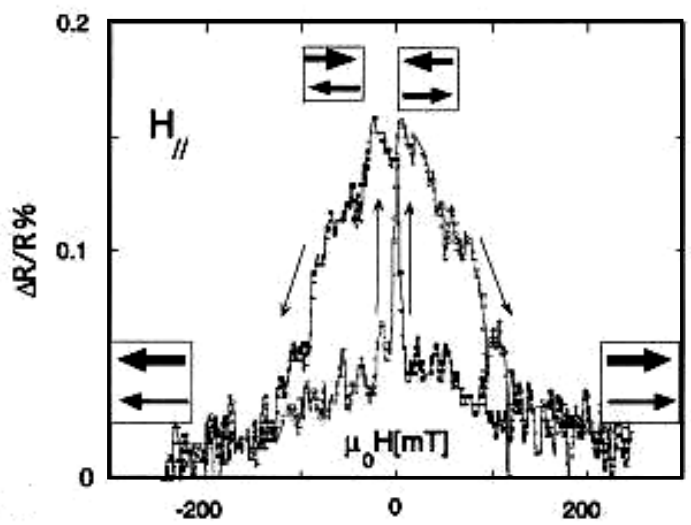

(a)

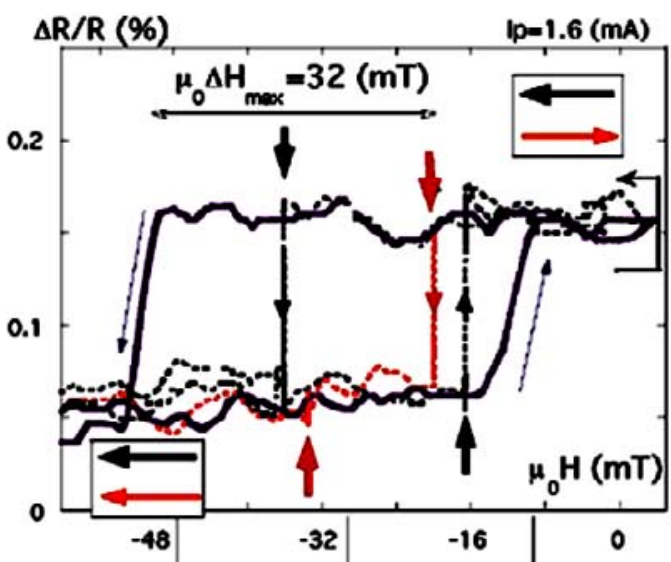

(b)

Fig. 15. GMR of spin-valve: (a) arrows indicate magnetic states of each layer with field and (b) Minor loop i.e. one layer fixed. Arrows are points of current injection demonstrating current provoked spin-flip of the free layer.

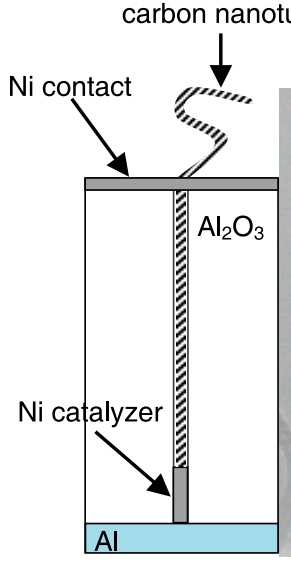

(a)

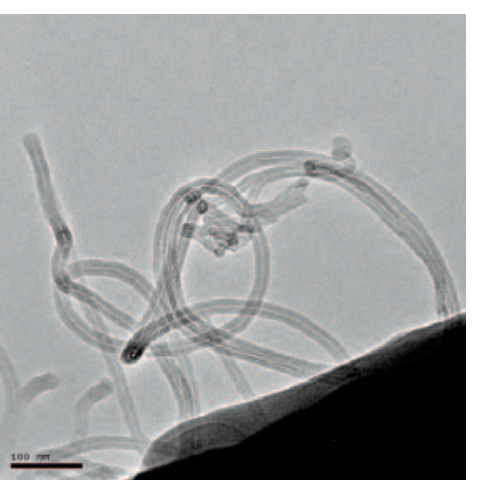

(b)
Fig. 16. Carbon nanotubes: (a) contact scheme and (b) TEM micrograph of carbon nanotubes in porous alumina.

oxalic acid at 40 volts for 10 minutes, depending on the desired length. At an anodization voltage of $40 \mathrm{~V}$ the alumina growth rate is about $150 \mathrm{~nm} /$ minute and the pore diameter is about $35-40 \mathrm{~nm}$. Nickel or cobalt nanowires catalysers of defined length were deposited in the pores. The membrane was then exposed to acetylene at 20 mbar and $630{ }^{\circ} \mathrm{C}$ in a tube furnace for 5 minutes. The carbon nanotubes catalytically grow from the top of the catalytic nanowires with an average diameter of $23 \mathrm{~nm}$. As can be seen from the TEM image in Figure 16b, the carbon nanotubes continue to grow from the pores beyond the surface of the membrane. $100 \mathrm{~nm}$ nickel or cobalt contacts were vapour sputtered afterwards.

The first characteristic of the electronic transport is the so-called zero bias anomaly (ZBA) observed in the differential conductance $G=d I / d V$ plotted as a function of the bias voltage. An other characteristic is that the temperature dependence of the conductance is a power law of the form $G(T)=G_{0} T^{-\alpha}$, where $\alpha$ is around 0.3 . But the most striking result is that all data at different $V_{\text {bias }}$ and temperatures collapse on a unique curve [190],

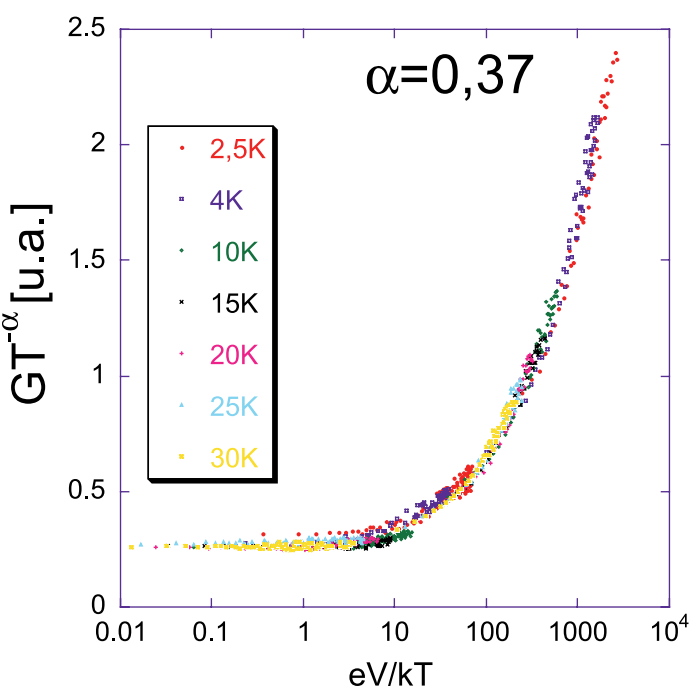

Fig. 17. Scaling of the conductivity of carbon nanotubes.

Figure 17. This is the manifestation of a scaling law; the quantity $G T^{-\alpha}$ is a function of the variable $\mathrm{eV} / \mathrm{kT}$. This behaviour was first interpreted in terms of Luttinger liquid theory, but it can also be described as a more general manifestation of Coulomb blockade effect [190]. The method of template synthesis allows one to perform a statistical study of the coefficient $\alpha$, as a function of the various parameters experimentally available. Note that the study with electrodeposited Te (see Sect. 5.3) shows the same behaviour with the scaling law, and comparable values of the scaling coefficient $\alpha$. The behaviour described above is hence not unique to carbon nanotubes. The problem requires further study.

Figure 18 shows that nanotubes contacted with cobalt exhibit a spin-dependent magnetoresistance (SD-MR) at low temperature; $\sim 3.6 \%$ at $2.5 \mathrm{~K}$. This magnetoresistance, however, disappears rapidly at temperatures above $20 \mathrm{~K}$.

Carbon nanotubes have chirality that determines many of their properties [191]. The crystalline orientation 


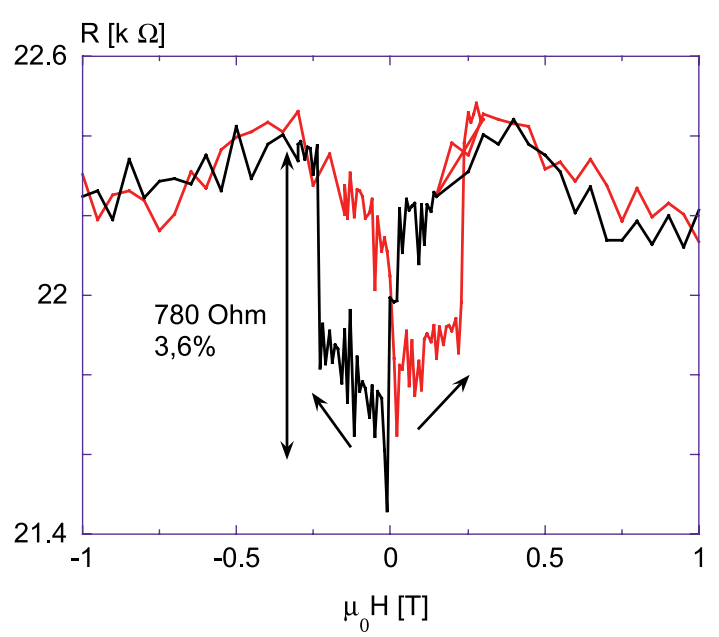

Fig. 18. Magnetoresistance of a cobalt contacted carbon nanotube $(T=2 \mathrm{~K})$.

and reproducibility of carbon nanotubes could be controlled by using an epitaxially oriented catalizing layer such as can be obtained be electrodeposition of cobalt or nickel [192-197].

\subsection{Silicon}

CVD growth of nanowires is very advanced with a large variety of materials already made [198]. It is now being performed in alumina templates for materials other than carbon nanotubes such as silicon [143]. In this case, however, the catalyser is gold, not a $3 \mathrm{~d}$ transition metal as for carbon nanotubes. Our own efforts in the template synthesis of silicon nanowires have already born fruit, Figure 19. This SEM micrograph shows a silicon nanowire exiting from an alumina pore. Figure 20 is a Raman spectra of silicon inside an alumina template and indicates that there is crystalline and amorphous silicon. Figure 21 is a current versus voltage curve for silicon nanowires in an alumina membrane and demonstrates the semiconductor properties of the silicone nanowires.

\subsection{Tellurium nanowires}

An important question arises about the specificities of the "nanoscopic molecules" like carbon nanotubes or Si nanorods with respect to semiconductor or semi-metal nanowires. The size and geometry are identical, but the properties are supposed to be different, due to the polycrystalline structure. Unlike the carbon nanotube molecules and the silicon nanorods, covalently bound semiconductor nanorods, such as tellurium, can be electrodeposited [199]. As is evident from Figure 22 the tellurium nanowires have very similar electron transport behaviour to the carbon nanotubes, Figure 17. The tellurium nanowires were grown and contacted in an aqueous solution in a manner similar to the nickel nanowires [199]. It is very surprising that the transport behaviour is so

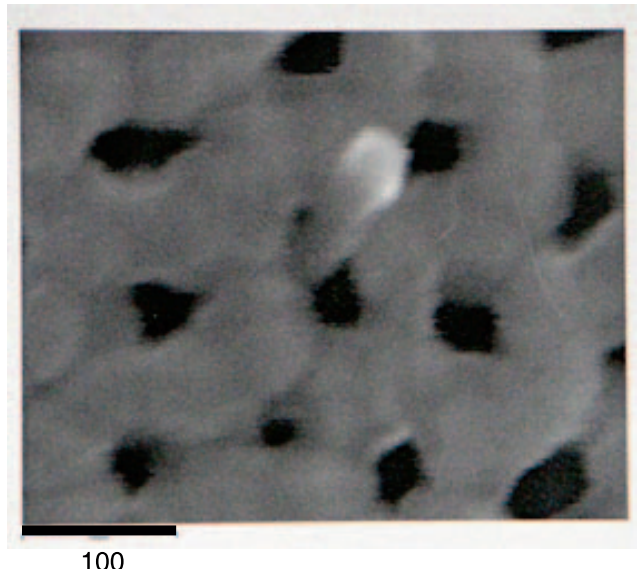

Fig. 19. SEM micrograph of a silicon nanowire exiting from a pore of an alumina membrane.

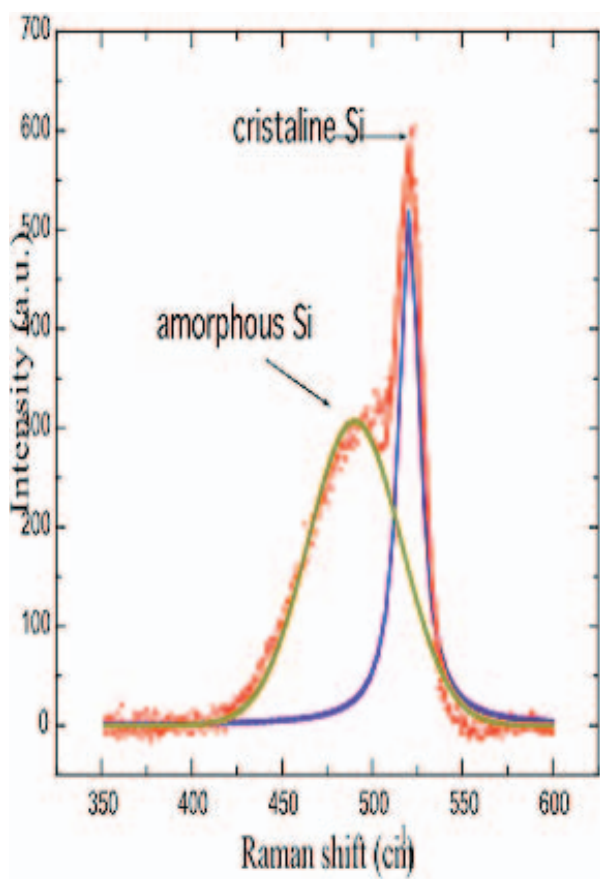

Fig. 20. Raman spectra of silicon nanowires in alumina.

similar and implies that something fundamental to these nanoscale materials is being observed.

\section{Carbon encapsulated nanoparticles}

In a more obscure approach than electrodeposition or CVD, magnetophoretic deposition was used for the template synthesis of granular nanowires [200]. When the building blocks for the template synthesis are atomic, like ions for electrodeposition, or molecular vapours, for CVD, then pore filling is relatively easy. When, however, the building blocks are a few nanometers in diameter, such as carbon encapsulated cobalt nanoparticles [201], convincing them to move into the pores becomes more difficult. 


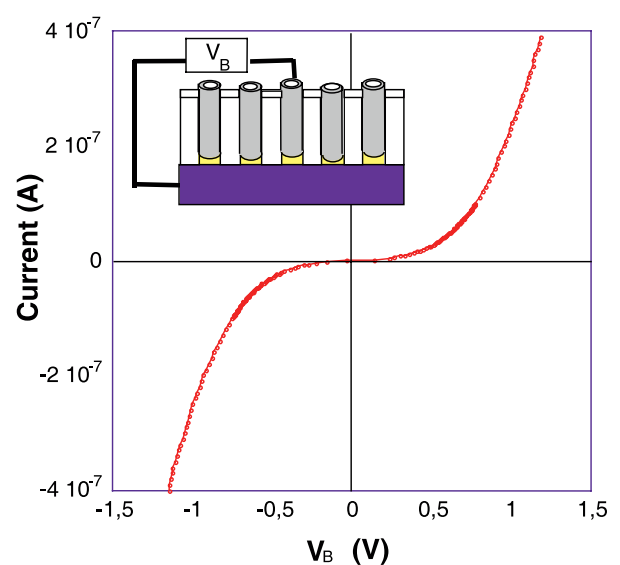

Fig. 21. $I$ versus $V$ curve of silicon nanowires in alumina.

A few physical techniques are available for filling nanopores with nanoparticles: mechanically forcing the particles into the pores, hydrodynamic pressure; using the pores as filters for the particles [202,203], eletrophoretic deposition; using the electrophoretic mobility of particles in a liquid, subjected to an electric field gradient, to drag the particles into the pores [204], and magnetophoretic deposition; using the magnetophoretic mobility of magnetic particles in a liquid, under the influence of a magnetic field gradient, to pull the particles into the pores. The first method is destructive and inefficient since only a shallow portion of the pores is filled. The second is inefficient at filling because once a pore becomes slightly blocked the pressure differences favour flow through empty pores until the whole process stops. These problems are inherent in any pressure driven filling process.

Electrophoresis is well known and has found many applications in medicine and materials [205-207]. Electrophoresis is the movement of particles, with a fixed surface charge, in a solvent by an electric field gradient [179]. Deposition by electrophoresis, electrophoretic deposition, has the advantage of being a bottom filling process, i.e. the particles fill the pores from the side with the highest field. Electrophoretic deposition has been used to place $\mathrm{Au}$ nanoparticles in alumina pores, but only a small percentage of the pores were filled [204]. Also, electrophoretic deposition often requires relatively clean, $\mathrm{H}_{2} \mathrm{O}$ free systems because water will electrolyse at voltages differences greater than $2 \mathrm{~V}$ [169] and normally electrophoretic deposition requires $10 \mathrm{~V}$ or more. The electrolysis generates $\mathrm{H}_{2}$ and $\mathrm{O}_{2}$ bubbles in the pores, which interfere with particle deposition and can delaminate a membrane from a substrate. Therefore, dry organic solvents are normally used. This is also a problem since these solvents can dissolve membranes, glue, or tape, which are often used in sample fabrication.

Magnetophoresis is well know in clinical fields [208] but is rare in materials science with very few applications [209-213]. Magnetophoretic deposition is analogous to electrophoretic deposition in that it uses a field gradient to move particles and it is also a bottom filling technique. The field gradient is, however, between two
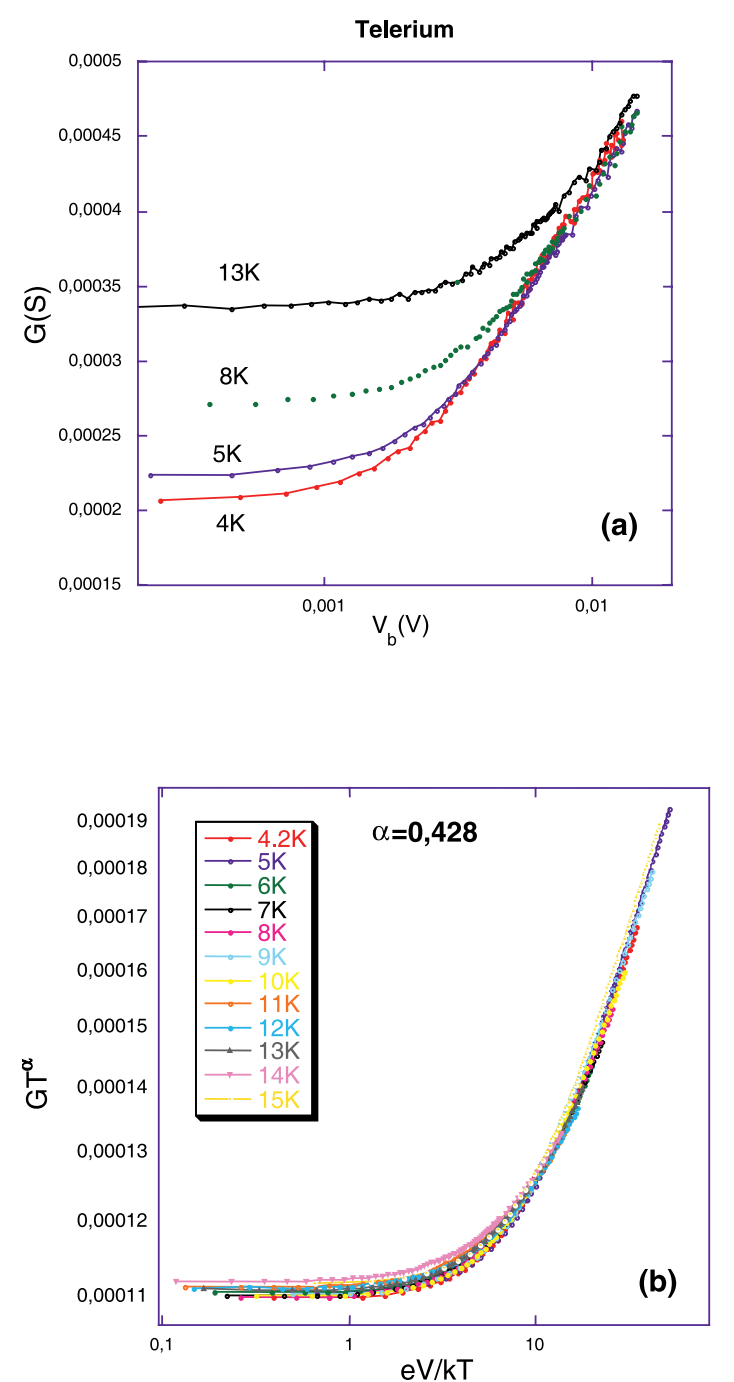

Fig. 22. Tellerium nanowires: (a) conductance as a function of the bias potential for different temperatures. (b) Same points presented in the scaling law $G T^{\alpha}=f(e V / k T)$.

magnetic poles, which can be outside of the solution that contains the particles. This is an experimental advantage. Interfering reactions, such as $\mathrm{H}_{2} \mathrm{O}$ electrolysis, are not encountered. Magnetic particles form chains and structures in magnetic fields [210-215]. Finally, magnetophoretic mobility is 1000 times greater than electrophoretic mobility [216]. The disadvantage of magnetophoretic deposition is that it requires magnetic particles.

There are many examples of techniques developed for using and changing the properties of the nanopores themselves for applications [217-219]. The use of nanoparticles to change properties of thin-films is well known [217,220-228]. The idea of using nanoparticles to modify and change the properties of nanowires and nanopores, however, is relatively unexplored [204]. The methods described here to put nanoparticles into nanopores to form the granular nanowires are the only 


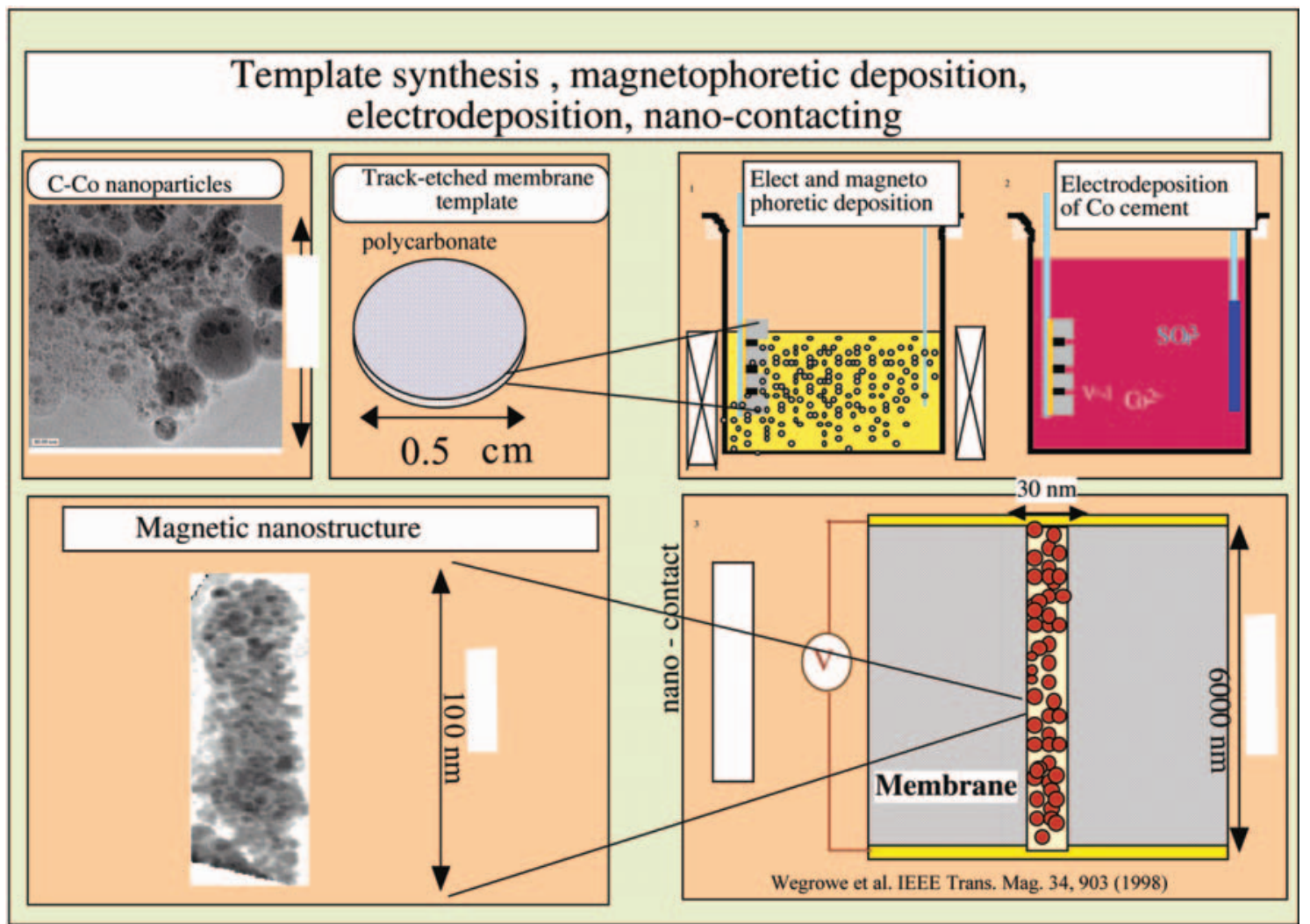

Fig. 23. Magnetophoretic deposition of granular nanowires.

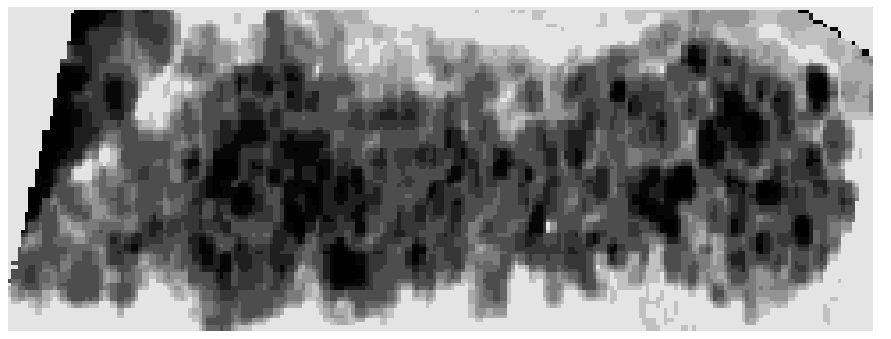

Fig. 24. TEM micrograph of a granular nanowire of carbon encapsulated cobalt nanoparticles in an electrodeposited cobalt matrix.

ones that the authors know of. Incorporation of magnetophoretic deposition with template synthesis is schematically shown in Figure 23.

The motivation for this study was to obtain samples that would demonstrate a ballistic magnetoresistive effect (BMR) in the context of template synthesis. If the size of a contact is nanometric or sub-nanometric, a ballistic junction is expected. In the presence of constrained magnetic domain walls at the scale of the junction, ballistic magnetoresistance can result [229-232]. The presence of tightly packed nanoscale particles in a magnetic matrix fulfils the requirements for BMR, Figure 24 [202,203,233].

For the magnetophoretic deposition, $0.1 \mathrm{ml}$ of $12 \mathrm{M}$ $\mathrm{HCl}$ is added to a $25 \mathrm{ml}$ container with the rinsed $\mathrm{Co} / \mathrm{C}$ nanoparticles in ethanol and is sonicated for 15 minutes. It is necessary to add the HCL to the particle/ethanol so- lution because it allows the particles to migrate towards a magnet pole by collapsing the double layer of the particles. Otherwise, the repulsion of the particles from each other prevents them from coalescing and results in a very stable suspension with no magnetophoretic mobility [234]. This assertion is supported by the fact that no magnetophoretic mobility is observed in ethanol/particle suspensions without added $\mathrm{HCl}$.

A polycarbonate membrane is positioned on the inside of the bottle that contains the $\mathrm{Co} / \mathrm{C}$ particles in ethanol. This bottle is then placed between the poles of an electromagnet, with the membrane next to one of the poles, Figures $23 \mathrm{c}$ and d. The poles are separated by about $3 \mathrm{~cm}$. The magnet is then turned on for at least 24 hours. In this configuration the magnetic field direction is perpendicular to the plane of the membrane, and thus the pores are parallel to it. The field strength at a pole is $1 \mathrm{~T}$ and $0.7 \mathrm{~T}$ between the poles, so a magnetic field gradient of $0.2 \mathrm{~T}$ per $\mathrm{cm}$ is used during magnetophoretic deposition. However, this gradient is not linear but parabolic [216].

The difference in the magnetic susceptibility of the particles and the ethanol causes the particles to migrate toward one of the poles of the magnet [216]. Since the membrane is between the particles and a magnetic pole, some of the particles migrate into the pores of the membrane.

Using 24 hours as the deposition time for the magnetophoretic deposition was arbitrary. No time dependent study of the process has been performed. Also, the strength of the magnet field used and the position 


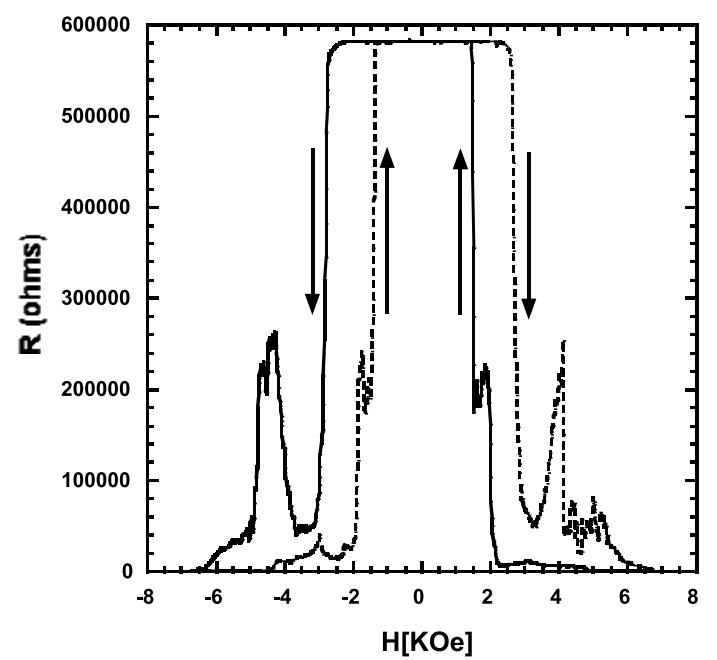

Fig. 25. Magnetoresistance curve of a granular nanowires.

of the membrane in the field during deposition are two other variables that were not studied. After the magnetophoretic deposition of the particles the sample preparation is identical to the processing for growing single contacted nanowires.

Samples that have particles in the pores have a very different Co electrodeposition. Membranes without particles contact within 20-30 seconds. Membranes with particles require $100 \mathrm{~s}$ to $35 \mathrm{~min}$ to contact. The cause of this is not certain, but it could be that dense clusters of particles in the pores slow migration of the Co contact solution due to the effective in diameter.

In Figure 24 nanoparticles of approximately $5 \mathrm{~nm}$ are evident. It is also clear that the diameter of the wire is greater than the 10 or $15 \mathrm{~nm}$ size stated by the membrane manufacturer. This is consistent with the findings of other studies and is the result of the ion track formation and the chemical etching of the membranes [8].

The magnetoresistance plot in Figure 25 is of electrodeposited Co nanowires with embedded nanoparticles. The main feature of these nanocomposites is the amplitudes of the magnetoresistance measured at room temperature and the abrupt changes in resistance with small changes in magnetic field. These signals were stable for a few hours to a day but eventually become stuck in a high or low resistance state and likely results from the reversible movement of matter at the atomic scale [233].

A BMR signal can only be measured if nanomechanical effects can be ruled out. Such signals have been measured in some samples with small resistances. The small resistances guarantees that there are no tunnel barriers, and hence, no structural defects, like holes in the Co matrix. Figure 26a shows magnetoresistance hysteresis loops measured at different temperatures for a sample with a temperature induced resistance change at $279 \mathrm{~K}$. The signal is stable and reproducible. The characteristic profile of the hysteresis is qualitatively different from that of the huge magnetoresistance effects of Figure 25. The hysteresis is well defined, with a coercive field varying from about 5 to
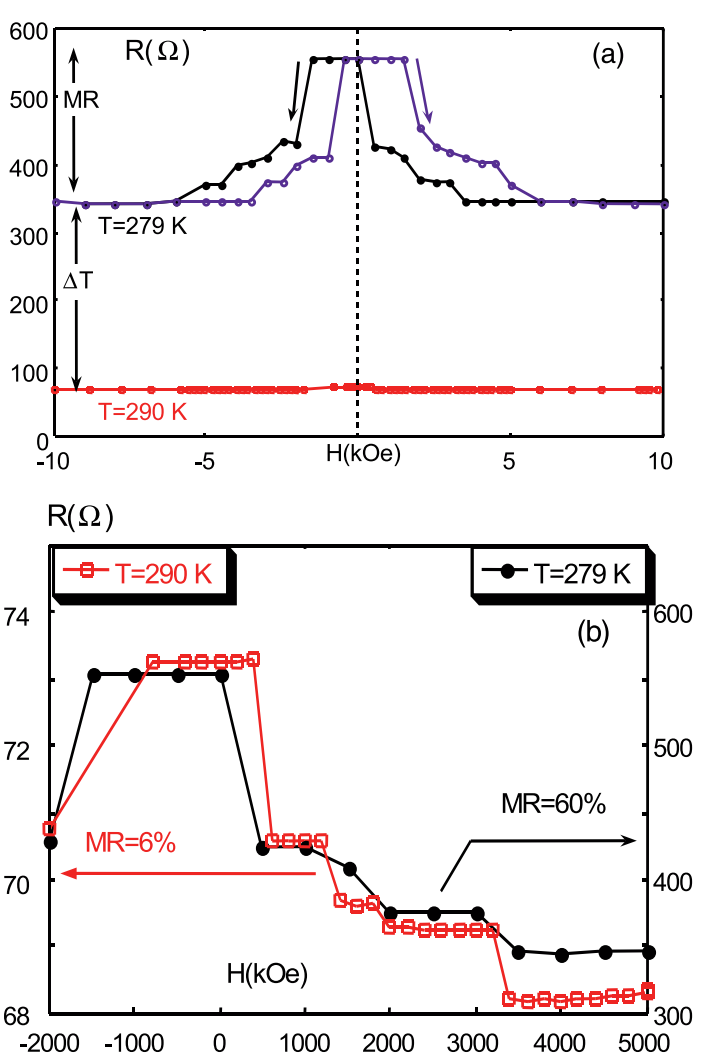

Fig. 26. Magnetoresistance of granular nanowires: (a) at 279 and $290 \mathrm{~K}$ and (b) superposition of curves from a.

$2 \mathrm{kOe}$ between 2 and $300 \mathrm{~K}$, as is expected for electrodeposited Co.

The important feature of Figure 26a is that the amplitude of the magnetoresistance changes drastically, $6 \%$ above the transition temperature $T_{t}$, and $60 \%$ below just below $T_{t}$, while the successive magnetic configurations observed in the hysteresis loop are unchanged. Figure 26b shows the superposition of the two signals of Figure 26a on a different scale. The similarity of the two curves is due to a change in the transport regime from diffusive to ballistic.

\section{Lateral anodization and transistors}

With two contacts we have made and studied many interesting phenomena such as magnetoresistance and electron transport in nanostructures. Two contacts are not enough if one wants to make a device such as a transistor for applications or research. A third contact or electrode is needed. An aspect of our research is the development of templates that allow placement of a third electrode close enough to the nanowires or carbon nanotubes for an electric field effect. At this time we have two possible template structures for field-effect transistors.

The first structure, Figure 27 upper left drawing, starts with an aluminum wire which is anodized perpendicular to its axis to form an isolation layer onto which a gate electrode is sputtered and then laterally anodized again 


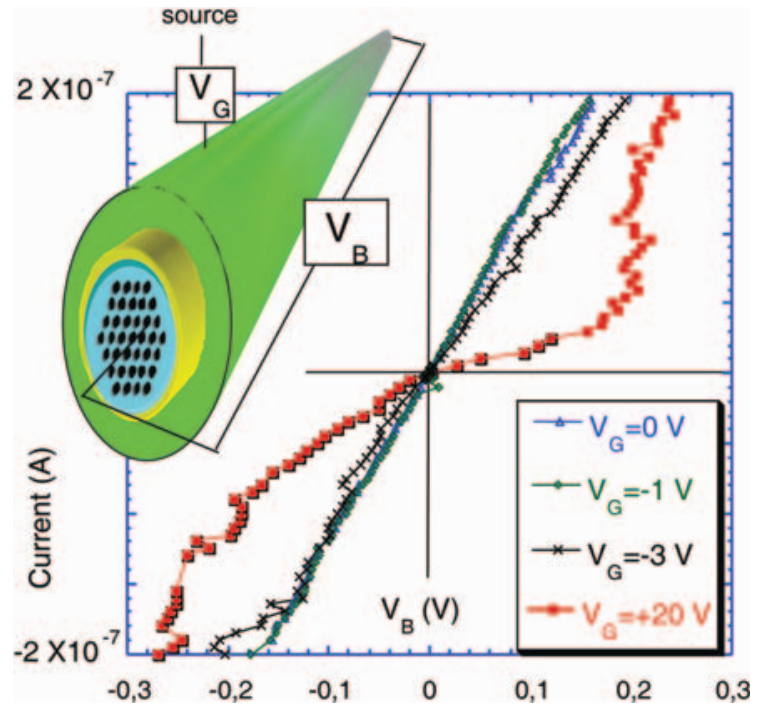

Fig. 27. Room temperature $I V$ curve of a tellurium nanowire transistor with different gate potentials.

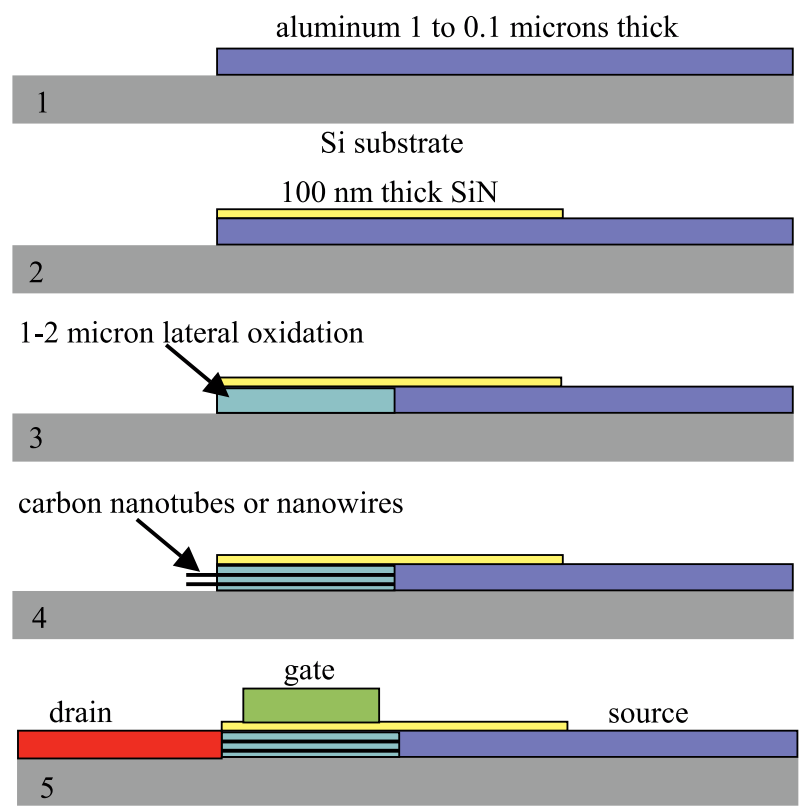

Fig. 28. Fabrication steps for lateral anodised alumina nanowire transistor.

to form a network of pores parallel to the wire as a template for the synthesis of nanostructures [235]. The nanostructures can then be grown and contacted with the gate electrode already in place. Preliminary results have been obtained with tellurium nanowires, Figure 27 room temperature $I V$ curve. This structure is interesting for us because it can be made totally in our lab without the need for a clean room or lithography.

The second structure, Figure 28, is formed by depositing an aluminum layer on a silicon substrate which is anodized parallel to the substrate to form a lateral template for the growth of nanostructures [236]. A gate electrode is then deposited onto the lateral template. The lateral anodization has been demonstrated with pore diameters as

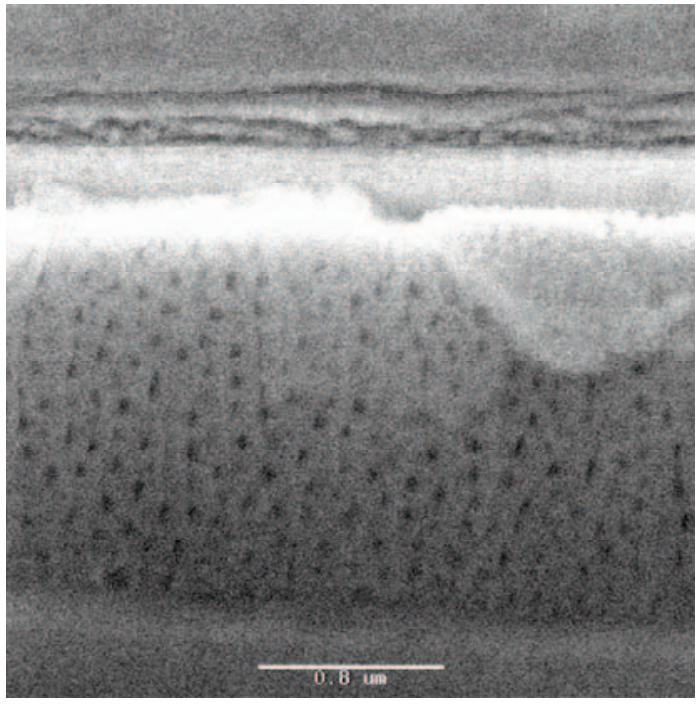

Fig. 29. SEM micrograph of lateral anodization.

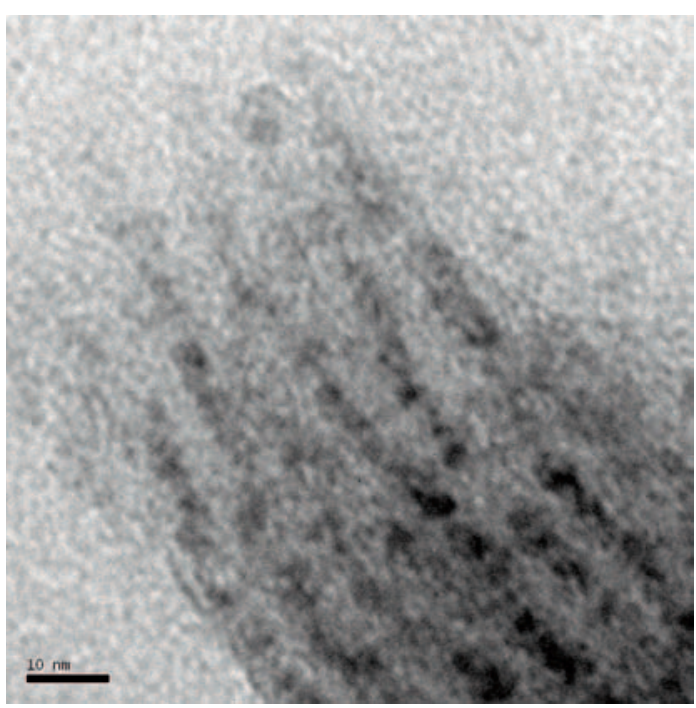

Fig. 30. TEM micrograph of tellurium nanowires with $5 \mathrm{~nm}$ diameter in an alumina template.

small as $5 \mathrm{~nm}$. The advantage of this approach is that it could be implemented into existing processor fabrication. The lateral oxidation has been successfully demonstrated, Figure 29. Figure 30 is of tellurium electrodeposited in $5 \mathrm{~nm}$ lateral pores. These two structures show the first results for these approaches to field-effect transistors based on anodized aluminum templates.

\section{Conclusion}

We have given a brief, though hopefully insightful, overview of the utility of template synthesis for our research. With polycarbonate templates and electrodeposition we made relatively simple structures, like the nickel nanowires, but we quickly advanced to more complicated and subtle structures, like the $\mathrm{Co} / \mathrm{Cu}$ multilayers, spinvalve structures, and electrodeposited semiconductors. 
Original results have been obtained in the context of current-induced magnetization switching. Each one of these systems demonstrated new and interesting phenomenon and are the focus of ongoing research in the field of spintronics and molecular electronics. A new material, the carbon encapsulated cobalt particles, was amenable to template synthesis because of the new technique of magnetophoretic deposition.

As our ambitions increased to include carbon nanotubes and silicon nanorods, we were able to find a template solution, in the form of anodised aluminium, for the high temperatures necessary for CVD. With these new systems we are observing new behaviours that we are just beginning to interpret in terms tunnelling with environmental Coulomb blockade effects.

Other semiconducting materials, such as electrodeposited tellurium, $\mathrm{ZnO}$ or $\mathrm{CuO}$ are being explored. A surprising conclusion of this comparative study is that semiconductors, either electrodeposited nanowires, CVD nanorods, or carbon nanotubes have the same characteristics at low temperatures. The common feature is the small tunnel barrier at the interfaces that could be due to the presence of oxides or to a Schottky barrier. The general behaviour of the zero bias anomaly follows quasi systematically a scaling law of the conductance $G$ as a function of temperature and bias voltage (of the form $G . T^{-\alpha}=(e V / k T)$, where $f$ is a simple function, $T$ is the temperature, $k$ the Boltzmann constant, $e V$ the electric potential). The electric transport can then be described by a single coefficient $\alpha$. This allows us to investigate single-electron tunnelling, or quantum dissipation effects in nanowires.

Finally, by inventing new templates small enough for the installation of a third electrode, we have created a new method to manipulate and control the physical phenomenon of the structures already studied. The first keeps very much in the spirit of our research to develop transistor devices in a 100\% bottom-up approach. The second is equally exciting because it offers the possibility of integrating our templates into the processes of existing device fabrication. The compatibility of template synthesis with top-down (e.g. CMOS) technology would allow one to control the nanometric scales with bottom-up techniques, and integrate them into the well-controlled micrometric and sub-micrometric device architectures.

The most significant aspect of the template is that it allows the nanoscale synthesis and macroscale contact of the infinite variety of materials and structures that can be made by solution phase chemistry, electrodeposition, gas phased chemistry, CVD, or physical methods, magnetophoresis, electrophoresis, or pressure. When this freedom is combined with the versatility and variety of the templates themselves, there are no fiscal or resource limits; now the only limit is imagination. The idea of template synthesis can then be generalized from membrane templates (with the concept of $2 \mathrm{D}$ structures) to the idea of a nanoskeleton, i.e. more complicated 3D structures. A nanodevice can be produced with different functionalities defined by the organization of the skeleton. Typically, one nanocontact can be coupled to a reservoir of heat in one or two sides (cooling system or Peltier-Seebeck devices), an other contact to a photonic system, other contacts link the system to electric generators or spintronics terminals, and other electrodes allow one to play with field effects and related phenomena. On the other hand, the role of the skeleton allows a structure to be reproduced with the best precision and it allows the development of new functionalities while preserving the rest unchanged, or without using an old, unnecessary functionality. This approach is of course largely exploited by the evolution of life, since the Precambrian period [237], for the development of suited functionalities. The studies presented here show that this bottom-up research programme, which is still at a very early stage of development, can be of fundamental interest for different vision of the future development of nanotechnologies, where the clean room may not play the central role.

We are very grateful for the indispensable help of our colleagues: Xavier Hoffer, Jean-François Dayen, Fahd Huwimel, Quang Anh, Cristina Ciornei, Jean-Marie Padovani, Corrado Mandoli, Anna Fontcuberta i Morral, Didier Pribat, Laurent Gravier, Aymeric Sallin, Jean-Philippe Ansermet, and JeanMarc Bonard.

\section{References}

1. S. Brueck, Opto Laser Europe June 2004, 27 (2004)

2. C.R. Martin, Science 266, 1961 (1994)

3. J. Vetter, R. Spohr, Nucl. Instrum. Methods in Physics Research B-Beam Interactions with Materials and Atoms 79, 691 (1993)

4. T.M. Whitney, J.S. Jiang, P.C. Searson, C.L. Chien, Science 261, 1316 (1993)

5. C.R. Martin, Chem. Mater. 8, 1739 (1996)

6. N.K. Raman, M.T. Anderson, C.J. Brinker, Chem. Mater. 8, 1682 (1996)

7. L. Piraux, S. Dubois, S. Demoustier-Champagne, Nucl. Instrum. Methods in Physics Research B 131, 357 (1997)

8. C. Schönenberger, B.M.I. van der Zande, L.G.J. Fokkink, M. Henny, C. Schmid, M. Kruger, A. Bachtold, R. Huber, H. Birk, U. Staufer, J. Phys. Chem. B 101, 5497 (1997)

9. S.K. Chakarvarti, J. Vetter, Radiat. Meas. 29, 149 (1998)

10. C.R. Martin, D.T. Mitchell, Anal. Chem. 70, 322A (1998)

11. W. Schwarzacher, O.I. Kasyutich, P.R. Evans, M.G. Darbyshire, G. Yi, V.M. Fedosyuk, F. Rousseaux, E. Cambril, D. Decanini, J. Magn. Magn. Mater. 199, 185 (1999)

12. A. Fert, L. Piraux, J. Magn. Magn. Mater. 200, 338 (1999)

13. A. Huczko, Appl. Phys.-Mater. Sci. Proces. 70, 365 (2000)

14. K. Rajeshwar, N.R. de Tacconi, C.R. Chenthamarakshan, Chem. Mater. 13, 2765 (2001)

15. P. Aranda, J.M. Garcia, J. Magn. Magn. Mater. 249, 214 (2002)

16. S. Banerjee, A. Dan, D. Chakravorty, J. Mater. Sci. 37, $4261(2002)$ 
17. M.L. Tian, J.U. Wang, J. Kurtz, T.E. Mallouk, M.H.W. Chan, Nanoletters 3, 919 (2003)

18. J.C. Bao, Z. Xu, H.M. Hong, X. Ma, Z.H. Lu, Scripta Mater. 50, 19 (2004)

19. D. Bera, S.C. Kuiry, S. Seal, J. Mater. 56, 49 (2004)

20. H. Chik, J.M. Xu, Mater. Sci. Eng. R 43, 103 (2004)

21. Z.S. Zhang, S.Y. Zhang, W.R. Li, Prog. Chem. 16, 26 (2004)

22. B. Bhushan, Springer Handbook of Nanotechnology (Springer-Verlag, Berlin Heidelberg, 2004)

23. G.E. Thompson, Thin Solid Films 297, 192 (1997)

24. R. Spohr, in Ion Tracks and Microtechnology, edited by K. Bethge (Vieweg, Braunschweig, 1990)

25. G.E. Possin, Rev. Sci. Instrum. 41, 772 (1970)

26. S. Kawai, R. Ueda, J. Electrochem. Soc. 112, 32 (1975)

27. W.D. Williams, N. Giordano, Rev. Sci. Instrum. 55, 410 (1984)

28. M.J. Theirney, C.R. Martin, J. Phys. Chem. 93, 2878 (1989)

29. C.A. Foss, G.L. Hornyak, J.A. Stockert, C.R. Martin, J. Phys. Chem. 96, 7497 (1992)

30. C.R. Martin, Chem. Mater. 8, 1739 (1996)

31. N.K. Raman, M.T. Anderson, C.J. Brinker, Chem. Mater. 8, 1682 (1996)

32. L. Piraux, S. Dubois, S. Demoustier Champagne, Nucl. Instrum. Methods in Physics Research B-Beam Interactions with Materials and Atoms 131, 357 (1997)

33. S.L. Pan, H.L. Zhang, Y. Peng, Z. Wang, H.L. Li, Chem. J. Chinese Univ. Chinese 20, 1622 (1999)

34. W. Schwarzacher, O.I. Kasyutich, P.R. Evans, M.G. Darbyshire, G. Yi, V.M. Fedosyuk, F. Rousseaux, E. Cambril, D. Decanini, J. Magn. Magn. Mater. 199, 185 (1999)

35. A. Huczko, Appl. Phys. A 70, 365 (2000)

36. T. Gao, G.W. Meng, J. Zhang, Y.W. Wang, C.H. Liang, J.C. Fan, L.D. Zhang, Appl. Phys. A-Mater. Sci. Proces. 73, 251 (2001)

37. N.I. Kovtyukhova, B.R. Martin, J.K.N. Mbindyo, T.E. Mallouk, M. Cabassi, T.S. Mayer, Mater. Sci. Eng. CBiomimetic and Supramolecular Systems 19, 255 (2002)

38. K.K. Lew, C. Reuther, A.H. Carim, J.M. Redwing, B.R. Martin, J. Vac. Sci. Technol. B 20, 389 (2002)

39. A.C. Galca, E.S. Kooij, H. Wormeester, C. Salm, V. Leca, J.H. Rector, B. Poelsema, J. Appl. Phys. 94, 4296 (2003)

40. S. Michotte, S. Matefi-Tempfli, L. Piraux, Supercond. Sci. Technol. 16, 557 (2003)

41. M.L. Tian, J.U. Wang, J. Kurtz, T.E. Mallouk, M.H.W. Chan, Nano Lett. 3, 919 (2003)

42. A.A. Zhukov, A.V. Goncharov, P.A.J. de Groot, P.N. Bartlett, M.A. Ghanem, H. Kupfer, R.J. Pugh, G.J. Tomka, IEE Proc.-Sci. Meas. Technol. 150, 257 (2003)

43. D. Bera, S.C. Kuiry, S. Seal, Jom 56, 49 (2004)

44. A. Blondel, J.P. Meier, B. Doudin, J.P. Ansermet, Appl. Phys. Lett. 65, 3019 (1994)

45. W. Wernsdorfer, K. Hasselbach, A. Benoit, B. Barbara, B. Doudin, J. Meier, J.P. Ansermet, D. Mailly, Phys. Rev. B 55, $11552(1997)$

46. J. Loffler, W. Wagner, H. VanSwygenhoven, J. Meier, B. Doudin, J.P. Ansermet, in Synthesis and Properties of Mechanically Alloyed and Nanocrystalline Materials, Pts 1 and 2 - Ismanam-96 (1997), pp. 699-704

47. A. Blondel, B. Doudin, J.P. Ansermet, J. Magn. Magn. Mater. 165, 34 (1997)
48. W. Wernsdorfer, B. Doudin, D. Mailly, K. Hasselbach, A. Benoit, J. Meier, J.P. Ansermet, B. Barbara, Phys. Rev. Lett. 77, 1873 (1996)

49. J. Meier, B. Doudin, J.P. Ansermet, J. Appl. Phys. 79, $6010(1996)$

50. B. Doudin, A. Blondel, J.P. Ansermet, J. Appl. Phys. 79, 6090 (1996)

51. B. Doudin, J.P. Ansermet, Nanostruct. Mater. 6, 521 (1995)

52. B. Voegeli, A. Blondel, B. Doudin, J.P. Ansermet, J. Magn. Magn. Mater. 151, 388 (1995)

53. A. Blondel, J. Meier, B. Doudin, J.P. Ansermet, K. Attenborough, P. Evans, R. Hart, G. Nabiyouni, W. Schwarzacher, J. Magn. Magn. Mater. 148, 317 (1995)

54. J. Meier, A. Blondel, B. Doudin, J.P. Ansermet, Helv. Phys. Acta 67, 761 (1994)

55. R. Ferré, K. Ounadjela, J.M. George, L. Piraux, S. Dubois, Phys. Rev. B 56, 14066 (1997)

56. L. Piraux, S. Dubois, C. Marchal, J.M. Beuken, L. Filipozzi, J.F. Despres, K. Ounadjela, A. Fert, J. Magn. Magn. Mater. 156, 317 (1996)

57. L. Piraux, S. Dubois, J.L. Duvail, K. Ounadjela, A. Fert, J. Magn. Magn. Mater. 175, 127 (1997)

58. R. Ferre, K. Ounadjela, J.M. George, L. Piraux, S. Dubois, Phys. Rev. B 56, 14066 (1997)

59. S. Dubois, J.L. Duvall, A. Fert, J.M. George, J.L. Maurice, L. Piraux, J. Appl. Phys. 81, 4569 (1997)

60. K. Ounadjela, R. Ferre, L. Louail, J.M. George, J.L. Maurice, L. Piraux, S. Dubois, J. Appl. Phys. 81, 5455 (1997)

61. S. Dubois, J.M. Beuken, L. Piraux, J.L. Duvail, A. Fert, J.M. George, J.L. Maurice, J. Magn. Magn. Mater. 165, 30 (1997)

62. L. Piraux, S. Dubois, E. Ferain, R. Legras, K. Ounadjela, J.M. George, J.L. Maurice, A. Fert, J. Magn. Magn. Mater. 165, 352 (1997)

63. S. Dubois, C. Marchal, J.M. Beuken, L. Piraux, J.L. Duvail, A. Fert, J.M. George, J.L. Maurice, Appl. Phys. Lett. 70, 396 (1997)

64. L. Piraux, S. Dubois, A. Fert, J. Magn. Magn. Mater. 159, L287 (1996)

65. F.J. Himpsel, J.E. Ortega, G.J. Mankey, R.F. Willis, Adv. Phys. 47, 511 (1998)

66. B. Doudin, G. Redmond, S.E. Gilbert, J.P. Ansermet, Phys. Rev. Lett. 79, 933 (1997)

67. E.Y. Tsymbal, A. Sokolov, I.F. Sabirianov, B. Doudin, Phys. Rev. Lett. 90 (2003)

68. C.R. Martin, Acc. Chem. Res. 28, 61 (1995)

69. L. Dauginet-De Pra, Nucl. Instrum. Methods in Physics Research B-Beam Interactions with Materials and Atoms 196, 81 (2002)

70. R. Vaidyanathan, J.L. Stickney, S.M. Cox, S.P. Compton, U. Happek, J. Electrochem. Sci. 559, 55 (2003)

71. N.I. Kovtyukhova, T.E. Mallouk, Chem. Euro. J. 8, 4355 (2002)

72. N.I. Kovtyukhova, B.R. Martin, J.K.N. Mbindyo, P.A. Smith, B. Razavi, T.S. Mayer, T.E. Mallouk, J. Phys. Chem. B 105, 8762 (2001)

73. R.T. Lv, C.B. Cao, H.Z. Zhai, D.Z. Wang, S.Y. Liu, H.S. Zhu, Solid State Commun. 130, 241 (2004)

74. C. Jia, C.G. Jin, W.F. Liu, W.L. Cai, L.Z. Yao, X.G. Li, Acta Phys. Chim. Sinica 20, 240 (2004) 
75. M. Lu, M.K. Li, L.B. Kong, X.Y. Guo, H.L. Li, Composites B-Eng. 35, 179 (2004)

76. R.Z. Chen, D.S. Xu, G.L. Guo, Y.Q. Tang, Chem. Phys. Lett. 377, 205 (2003)

77. L. Wang, Y.F. Zhu, Chem. Lett. 32, 594 (2003)

78. H.Q. Cao, X.Q. Qiu, Y. Liang, Q.M. Zhu, M.J. Zhao, Appl. Phys. Lett. 83, 761 (2003)

79. K.K. Lew, J.M. Redwing, J. Cryst. Growth 254, 14 (2003)

80. Z. Miao, D.S. Xu, J.H. Ouyang, G.L. Guo, X.S. Zhao, Y.Q. Tang, Nano Lett. 2, 717 (2002)

81. J. Zhang, X. Wang, X. Peng, L. Zhang, Appl. Phys. AMater. Sci. Proces. 75, 485 (2002)

82. H.W. Liu, S.M. Hou, G.M. Zhang, Z.Y. Shen, W.M. Liu, J.L. Wu, Z.Q. Xue, E. Roy, K.Y. Zhang, Acta Phys.Chim. Sinica 18, 359 (2002)

83. X.Y. Zhang, L.D. Zhang, Y. Lei, L.X. Zhao, Y.Q. Mao, J. Mater. Chem. 11, 1732 (2001)

84. D.S. Xu, Y.J. Xu, D.P. Chen, G.L. Guo, L.L. Gui, Y.Q. Tang, Chem. Phys. Lett. 325, 340 (2000)

85. D.S. Xu, D.P. Chen, Y.J. Xu, X.S. Shi, G.L. Guo, L.L. Gui, Y.Q. Tang, Pure Appl. Chem. 72, 127 (2000)

86. G. Yi, W. Schwarzacher, Appl. Phys. Lett. 74, 1746 (1999)

87. S. Michotte, Int. J. Mod. Phys. B 17, 4601 (2003)

88. S. Michotte, S. Matefi-Tempfli, L. Piraux, Phys. CSupercond. Appl. 391, 369 (2003)

89. G. Stenuit, S. Michotte, J. Govaerts, L. Piraux, Euro. Phys. J. B 33, 103 (2003)

90. S. Michotte, S. Matefi-Tempfli, L. Piraux, Appl. Phys. Lett. 82, 4119 (2003)

91. J. Chen, R. Könenkamp, Appl. Phys. Lett. 82, 4782 (2003)

92. L. Augustin, L.F. Chi, H. Fuchs, S. Höppner, S. Rakers, C. Röthig, T. Schwaack, F. Starrberg, Appl. Surf. Sci. 141, 219 (1999)

93. L. Sun, P.C. Searson, C.L. Chien, Phys. Rev. B 61, R6463 (2000)

94. L. Sun, P.C. Searson, C.L. Chien, Appl. Phys. Lett. 79, $4429(2001)$

95. Poretics, Pleasanton, USA

96. J.P. O'Sullivan, G.C. Wood, Proc. R. Soc. London A Math. Phys. Sci. 317, 511 (1970)

97. G.E. Thompson, R.C. Furneaux, G.C. Wood, J.A. Richardson, J.S. Goode, Nature 272, 433 (1978)

98. Y. Xu, G.E. Thompson, G.C. Wood, Electrochim. Acta 27, 1623 (1982)

99. H. Masuda, K. Fukuda, Science 268, 1466 (1995)

100. O. Jessensky, F. Muller, U. Gosele, J. Electrochem. Soc. 145, 3735 (1998)

101. O. Jessensky, F. Muller, U. Gosele, Appl. Phys. Lett. 72, 1173 (1998)

102. A.P. Li, F. Muller, A. Birner, K. Nielsch, U. Gosele, J. Appl. Phys. 84, 6023 (1998)

103. L. Ba, W.S. Li, J. Phys. D Appl. Phys. 33, 2527 (2000)

104. H.D.L. Lira, R. Paterson, J. Membrane Sci. 206, 375 (2002)

105. K. Nielsch, J. Choi, K. Schwirn, R.B. Wehrspohn, U. Gosele, Nano Lett. 2, 677 (2002)

106. Y.C. Sui, B.Z. Cui, L. Martinez, R. Perez, D.J. Sellmyer, Thin Solid Films 406, 64 (2002)

107. S. Ono, N. Masuko, Surf. Coatings Technol. 169, 139 (2003)
108. X. Wang, G.R. Han, Microelectron. Eng. 66, 166 (2003) 109. J.B. Bai, J.L. Vignes, T. Fournier, D. Michel, Adv. Eng. Mater. 4, 701 (2002)

110. X. Chen, Z. Hu, X.Z. Wang, Q. Wu, Y. Chen, S.G. Yang, Y.W. Du, Chem. J. Chinese Univ. 22, 731 (2001)

111. F.H. Kaatz, M.P.S., D.L. Overmyer, P.P. Provencio, J.L. Jackson, Mater. Sci. Eng. C 23, 141 (2003)

112. J. Haruyama, I. Takesue, S. Kato, K. Takazawa, Y. Sato, Appl. Surf. Sci. 175, 597 (2001)

113. G.L. Hornyak, A.C. Dillon, P.A. Parilla, J.J. Schneider, N. Czap, K.M. Jones, F.S. Fasoon, A. Mason, M.J. Heben, Nanostruct. Mater. 12, 83 (1999)

114. W.C. Hu, D.W. Gong, Z. Chen, L.M. Yuan, K. Saito, C.A. Grimes, P. Kichambare, Appl. Phys. Lett. 79, 3083 (2001)

115. W.C. Hu, L.M. Yuan, Z. Chen, D.W. Gong, K. Saito, J. Nanosci. Nanotechnol. 2, 203 (2002)

116. M.J. Kim, T.Y. Lee, J.H. Choi, J.B. Park, J.S. Lee, S.K. Kim, J.-B. Yoo, C.-Y. Park, Diamond Related Mater. 12, $870(2003)$

117. Y.C. Sui, B.Z. Cui, R. Guardian, D.R. Acosta, L. Martinez, R. Perez, Carbon 40, 1011 (2002)

118. C.W. Wang, M.K. Li, S.L. Pan, H.L. Li, Chinese Sci. Bull. 45, $1373(2000)$

119. C.W. Wang, M.K. Li, H.L. Li, Sci. China Series A-Math. Phys. Astron. 44, 234 (2001)

120. X.H. Wang, Z. Hu, Q. Wu, Y. Chen, Catal. Today 72, $205(2002)$

121. X.Y. Zhang, L.D. Zhang, M.J. Zheng, G.H. Li, L.X. Zhao, J. Cryst. Growth 223, 306 (2001)

122. X.Y. Zhang, L.D. Zhang, G.H. Li, L.X. Zhao, Mater. Sci. Eng. A 308, 9 (2001)

123. K. Nielsch, R. Hertel, R.B. Wehrspohn, J. Barthel, J. Kirschner, U. Gosele, S.F. Fischer, H. Kronmuller, IEEE Trans. Magn. 38, 2571 (2002)

124. Y. Hirata, H. Kyoda, T. Iwamoto, K. Hamasaki, J. Ceram. Soc. Jpn 103, 460 (1995)

125. B.B. Lakshmi, C.J. Patrissi, C.R. Martin, Chem. Mater. 9, $2544(1997)$

126. J.W. Pell, K.M. Delak, H.C. zur Loye, Chem. Mater. 10, 1764 (1998)

127. P. Sawunyama, A. Yasumori, K. Okada, Mater. Res. Bull. 33, 795 (1998)

128. H. Imai, Y. Takei, K. Shimizu, M. Matsuda, H. Hirashima, J. Mater. Chem. 9, 2971 (1999)

129. K. Nielsch, F. Muller, A.P. Li, U. Gosele, Adv. Mater. 12, $582(2000)$

130. G. Shi, C.M. Mo, W.L. Cai, L.D. Zhang, Solid State Commun. 115, 253 (2000)

131. J.H. Wu, L. Pu, J.P. Zhou, Y.F. Mei, J.M. Zhu, X.M. Bao, Chinese Phys. Lett. 17, 451 (2000)

132. L.D. Zhang, G.W. Meng, F. Phillipp, Mater. Sci. Eng. A-Struct. Mater. Prop. Microstruct. and Proces. 286, 34 (2000)

133. M. Zheng, L. Menon, H. Zeng, Y. Liu, S. Bandyopadhyay, R.D. Kirby, D.J. Sellmyer, Phys. Rev. B 62, 12282 (2000)

134. H.Q. Cao, Y. Xu, J.M. Hong, H.B. Liu, G. Yin, B.L. Li, C.Y. Tie, Z. Xu, Adv. Mater. 13, 1393 (2001)

135. B. Cheng, E.T. Samulski, J. Mater. Chem. 11, 2901 (2001)

136. K.Y. Jiang, Y. Wang, J.J. Dong, L.L. Gui, Y.Q. Tang, Langmuir 17, 3635 (2001) 
137. A. Yasumori, H. Shinoda, Y. Kameshima, S. Hayashi, K. Okada, J. Mater. Chem. 11, 1253 (2001)

138. H. Zhu, S.G. Yang, G. Ni, D.L. Yu, Y.W. Du, Scripta Mater. 44, 2291 (2001)

139. Y.J. Glanville, D.G. Narehood, P.E. Sokol, A. Amma, T. Mallouk, J. Mater. Chem. 12, 2433 (2002)

140. Y.T. Pang, G.W. Meng, L.D. Zhang, W.J. Shan, X.Y. Gao, A.W. Zhao, Y.Q. Mao, J. Phys.-Cond. Matter 14, 11729 (2002)

141. Y.H. Wang, Y.Q. Xu, W.L. Cai, J.M. Mo, Acta Phys. Chim. Sinica 18, 943 (2002)

142. H. Zeng, S. Michalski, R.D. Kirby, D.J. Sellmyer, L. Menon, S. Bandyopadhyay, J. Phys.-Cond. Matter 14, $715(2002)$

143. K.-K. Lew, J.M. Redwing, J. Cryst. Growth 254, 14 (2003)

144. S.U. Yuldashev, S.W. Choi, T.W. Kang, L.A. Nosova, J. Korean Phys. Soc. 42, S216 (2003)

145. W.B. Choi, J.U. Chu, K.S. Jeong, E.J. Bae, J.-W. Lee, J.-J. Kim, J.-O. Lee, Appl. Phys. Lett. 79, 3696 (2001)

146. S.Z. Chu, K. Wada, S. Inoue, S. Todoroki, Y.K. Takahashi, K. Hono, Chem. Mater. 14, 4595 (2002)

147. J.S. Lee, G.H. Gu, H. Kim, J.S. Shu, I. Han, N.S. Lee, J.M. Kim, G.-S. Park, Synthetic Met. 124, 307 (2001)

148. J.C. Bao, Z. Xu, Chinese J. Inorg. Chem. 18, 965 (2002)

149. O. Jessensky, F. Müller, U. Gösele, Appl. Phys. Lett. 72, $1173(1998)$

150. C. Xu, Q. Xue, Y. Zhong, Y. Cui, L. Ba, B. Zhao, N. Gu, Nanotechnology 13, 47 (2002)

151. A.P. Li, F. Müller, A. Birner, K. Nielsch, U. Gösele, J. Appl. Phys. 84, 6023 (1998)

152. T. Thurn-Albrecht, J. Schotter, G.A. Kästle, N. Emley, T. Shibauchi, K. Guarini, C.T. Black, M.T. Tuominen, T.P. Russell, Science 290, 2126 (2000)

153. J.E. Wegrowe, S.E. Gilbert, D. Kelly, B. Doudin, J.P. Ansermet, IEEE Trans. Magn. 34, 903 (1998)

154. J.E. Wegrowe, D. Kelly, A. Franck, S.E. Gilbert, J.P. Ansermet, Phys. Rev. Lett. 82, 3681 (1999)

155. J.E. Wegrowe, D. Kelly, Y. Jaccard, P. Guittienne, J.P. Ansermet, Europhys. Lett. 45, 626 (1999)

156. Y. Jaccard, P. Guittienne, D. Kelly, J.E. Wegrowe, J.P. Ansermet, Phys. Rev. B 62, 1141 (2000)

157. P. Guittienne, J.E. Wegrowe, D. Kelly, J.P. Ansermet, IEEE Trans. Magn. 37, 2126 (2001)

158. J.E. Wegrowe, D. Kelly, T. Truong, P. Guittienne, J.P. Ansermet, Europhys. Lett. 56, 748 (2001)

159. J.E. Wegrowe, P. Guittienne, D. Kelly, X. Hoffer, J.P. Ansermet, Abstracts of Papers of the Am. Chem. Soc. 221, U371 (2001)

160. J.E. Wegrowe, D. Kelly, X. Hoffer, P. Guittienne, J.P. Ansermet, J. Appl. Phys. 89, 7127 (2001)

161. L. Gravier, J.E. Wegrowe, T. Wade, A. Fabian, J.P Ansermet, IEEE Trans. Magn. 38, 2700 (2002)

162. P. Guittienne, L. Gravier, J.E. Wegrowe, J.P. Ansermet, J. Appl. Phys. 92, 2743 (2002)

163. J.E. Wegrowe, X. Hoffer, P. Guittienne, A. Fabian, L. Gravier, T. Wade, J.P. Ansermet, J. Appl. Phys. 91, 6806 (2002)

164. J.E. Wegrowe, A. Fabian, P. Guittienne, X. Hoffer, D. Kelly, J.P. Ansermet, E. Olive, Appl. Phys. Lett. 80, 3775 (2002)

165. J.E. Wegrowe, A. Sallin, A. Fabian, A. Comment, J.M. Bonard, J.P. Ansermet, Phys. Rev. B 65 (2002)
166. A. Fabian, C. Terrier, S.S. Guisan, X. Hoffer, M. Dubey, L. Gravier, J.P. Ansermet, J.E. Wegrowe, Phys. Rev. Lett. 91 (2003)

167. D. Kelly, J.E. Wegrowe, T.K. Truong, X. Hoffer, J.P. Ansermet, Phys. Rev. B 68 (2003)

168. J.E. Wegrowe, Phys. Rev. B 68 (2003)

169. A.J. Bard, L.R. Faulkner, Electrochemical Methods: Fundamentals and Applications (John Wiley, Sons, New York, 1980)

170. W. Wu, J.B. DiMaria, H.G. Yoo, S. Pan, L.J. Rothberg, Y. Zhang, Appl. Phys. Lett. 84, 966 (2004)

171. T.R. McGuire, R.I. Potter, IEEE Trans. Magn. MAG11, $1018(1975)$

172. L. Berger, J. Appl. Phys. 55, 1954 (1984)

173. L. Berger, Phys. Rev. B 54, 9353 (1996)

174. C. Slonczewski, J. Magn. Magn. Mater. 159, L1 (1996)

175. C. Slonczewski, J. Magn. Magn. Mater. 195, L261 (1999)

176. M.N. Baibich, J.M. Broto, A. Fert, V.D. Nguyen, F. Petroff, P. Eitenne, G. Creuzet, A. Friederich, J. Chazelas, Phys. Rev. Lett. 61, 2472 (1988)

177. J.M. Daughton, GMR applications, J. Magn. Magn. Mater. 192, 334 (1999)

178. L. Gravier, A. Fabian, A. Rudolf, A. Cachin, J.E. Wegrowe, J.P. Ansermet, J. Magn. Magn. Mater. 271, $153(2004)$

179. P.H. Rieger, Electrochemistry (Prentice-Hall, Inc., Englewood Cliffs, New Jersey, 1987)

180. L. Peter, Q.X. Liu, Z. Kerner, I. Bakonyi, Electrochim. Acta 49, 1513 (2004)

181. P.R. Evans, G. Yi, W. Schwarzacher, Appl. Phys. Lett. 76, $481(2000)$

182. G.R. Pattanaik, D.K. Pandya, S.C. Kashyap, Thin Solid Films 433, 247 (2003)

183. E. Gomez, A. Labarta, A. Llorente, E. Valles, Electrochim. Acta 48, 1005 (2003)

184. D. Porath, G. Cuniberti, R. Di Felice, in Long-Range Charge Transfer in DNA II, edited by G. Schuster (Springer, 2004), 183

185. J.J. Zhao, R.H. Xie, J. Nanosci. Nanotechnol. 3, 459 (2003)

186. J.J. Schneider, J. Engstler, S. Franzka, K. Hofmann, B. Albert, J. Ensling, P. Gutlich, P. Hildebrandt, S. Dopner, W. Pfleging, B. Gunther, G. Muller, Chem. Eur. J. 7, 2888 (2001)

187. J.C. Bao, Q.F. Zhou, J.M. Hong, Z. Xu, Appl. Phys. Lett. 81, 4592 (2002)

188. J. Haruyama, I.O. Takesue, T. Hasegawa, Phys. B-Cond. Matter 323, 252 (2002)

189. J. Haruyama, I. Takesue, T. Hasegawa, Phys. Rev. B 6503, $033402(2002)$

190. X. Hoffer, C. Klinke, J.-M. Bonard, L. Gravier, J.-E. Wegrowe, Europhys. Lett. 67, 103 (2004)

191. M.S. Dresselhaus, H. Dai, MRS Bull. 29, 237 (2004)

192. J. Pflaum, D. Spoddig, J. Pelzl, J.L. Bubendorff, J.P. Bucher, Surf. Sci. 482, 1035 (2001)

193. J.L. Bubendorff, C. Meny, E. Beaurepaire, P. Panissod, J.P. Bucher, Eur. Phys. J. B 17, 635 (2000)

194. I. Chado, S. Padovani, F. Scheurer, J.P. Bucher, Appl. Surf. Sci. 164, 42 (2000)

195. S. Padovani, F. Scheurer, J.P. Bucher, Europhys. Lett. 45, 327 (1999)

196. S. Padovani, P. Molinas-Mata, F. Scheurer, J.P. Bucher, Appl. Phys. A-Mater. Sci. Proces. 66, S1199 (1998) 
197. J.L. Bubendorff, L. Cagnon, V. CostaKieling, J.P. Bucher, P. Allongue, Surf. Sci. 384, L836 (1997)

198. C.N.R. Rao, F.L. Deepak, G. Gundiah, A. Govindaraj, Progr. Solid State Chem. 31, 5 (2003)

199. A. Zhao, L. Zhang, Y. Pang, C. Ye, Appl. Phys. A 28, January (2004), online

200. J.E. Wegrowe, T. Wade, X. Hoffer, L. Gravier, J.M. Bonard, J.P. Ansermet, Phys. Rev. B 67 (2003)

201. J.-M. Bonard, S. Seraphin, Wegrowe, J.-E., J. Jiao, A. Châtelain, Chem. Phys. Lett. 343, 251 (2001)

202. J.-E. Wegrowe, A. Sallin, A. Fàbiàn, A. Comment, J.-M. Bonard, J.-P. Ansermet, Phys. Rev. B 65, 12407 (2001)

203. A. Sallin, in Institut de physique expérimentale (IPE) (École Polytechnique Fédérale de Lausanne, Lausanne, 2000), 100

204. G. Hornyak, M. Kröll, R. Pugin, T. Sawitowski, G. Schmid, J.-O. Bovin, G. Karsson, H. Hofmeister, S. Hopfe, Chem.-A Eur. J. 3, 1951 (1997)

205. L.J. Jin, J. Ferrance, J.P. Landers, Biotechniques 31, $1332(2001)$

206. A.M. Affoune, P.L.V. Prasad, H. Sato, T. Enoki, Langmuir 17, 547 (2001)

207. E. Maillard-Schaller, O.M. Kuettel, L. Diederich, L. Schlapbach, V.V. Zhirnov, P.I. Belobrov, Diamond and Related Mater. 8, 805 (1999)

208. B.W. Barry, Eur. J. Pharm. Sci. 14, 101 (2001)

209. J.L. Katz, Y. Xing, R.C. Cammarata, J. Mater. Res. 14, 4457 (1999)

210. M. Giersig, M. Hilgendorff, J. Phys. D Appl. Phys. 32, L111 (1999)

211. M. Hilgendorff, B. Tesche, M. Giersig, Aust. J. Chem. 54, $497(2001)$

212. U. Wiedwald, M. Spasova, M. Farle, M. Hilgendorff, M. Gijersig, J. Vac. Sci. Technol. A 19, 1773 (2001)

213. E.L. Bizdoaca, M. Spasova, M. Farle, M. Hilgendorff, L.M. Liz-Marzan, F. Caruso, J. Vac. Sci. Technol. A 21, 1515 (2003)

214. M.A. Hayes, N.A. Polson, A.A. Garcia, Langmuir 17, 2866 (2001)

215. C.B. Murry, S. Sun, H. Doyle, T. Betley, (Co, Ni, Fe) Nanoparticles and Their Assembly into Nanoparticle Superlattices, MRS Bull. 26, 985 (2001)

216. L.L. Schramm, B.W. Clark, Colloids and Surf. 7, 135 (1983)
217. K.B. Jirage, J.C. Hulteen, C.R. Martin, Science 278, 655 (1997)

218. M. Nishizawa, V.P. Menon, C.R. Martin, Science 268, $700(1995)$

219. J.C. Hulteen, V.P. Menon, C.R. Martin, J. Chem. Soc. Faraday Trans. 92, 4029 (1996)

220. K. Yakushiji, S. Mitani, K. Takahashi, S. Maekawa, H. Imamura, H. Fujimori, Appl. Phys. Lett. 78, 515 (2001)

221. M. Alonso-Sañudo, J.J. Blackwell, K. O'Grady, J.M. González, F. Cebollada, M.P. Morales, J. Magn. Magn. Mater. 221, 207 (2000)

222. A. Bezryadin, C. Dekker, Appl. Phys. Lett. 71, 1273 (1997)

223. V. Dupuis, J. Tuaillon, B. Prevel, A. Perez, P. Melinon, Z. Phys. D 40, 155 (1997)

224. M. Holdenried, B. Hackenbroich, H. Micklitz, J. Magn. Magn. Mater. 231, L13 (2001)

225. S. Rubin, M. Holdenried, H. Micklitz, Eur. Phys. J. B 5, $23(1998)$

226. P. Sheng, B. Abeles, Y. Arie, Phys. Rev. Lett. 31, 44 (1973)

227. J. Tang, L. Feng, J.A. Wiemann, Appl. Phys. Lett. 74, $2522(1999)$

228. T. Taniyama, Y. Kitamoto, Y. Yamazaki, J. Appl. Phys. 89, 7693 (2001)

229. N. Garcia, G.G. Qiang, I.A. Saveliev, Appl. Phys. Lett. 80, 1785 (2002)

230. N. Garcia, M. Muñoz, Y.-W. Zhao, Phys. Rev. Lett. 82, 2923 (1999)

231. N. Garcia, H. Rohrer, I.G. Saveliev, Y.-W. Zhao, Phys. Rev. Lett. 85 (2000)

232. J.J. Versluijs, M.A. Bari, J.M.D. Coey, Phys. Rev. Lett. 87, 26601 (2001)

233. J.-E. Wegrowe, T. Wade, X. Hoffer, L. Gravier, J.-M. Bonard, J.-P. Ansermet, Phys. Rev. B 67, 104418 (2003)

234. J.d. Vicente, A.V. Delgado, R.C. Plaza, J.D.G. Duran, F. Gonzalez-Caballero, Langmuir 16, 7954 (2000)

235. T. Wade, J.-E. Wegrowe, Patent application (École Polytechnique, France, 2003)

236. D. Pribat, J.-E. Wegrowe, T. Wade, Patent application (École Polytechnique, France, 2003)

237. S.J. Gould, Wonderful Life: The Burgess Shale and the Nature of History (W.W. Norton, Co., New York, 1989) 